\title{
Structural Characterization, Antioxidant Activity, and Biomedical Application of Astragalus Polysaccharide Degradation Products
}

\author{
Jian-Min Wang, Xin-Yuan Sun $(\mathbb{D}$, and Jian-Ming Ouyang $\mathbb{D}$ \\ Institute of Biomineralization and Lithiasis Research, Jinan University, Guangzhou 510632, China \\ Correspondence should be addressed to Xin-Yuan Sun; sunxinyuan1985@163.com and Jian-Ming Ouyang; toyjm@jnu.edu.cn
}

Received 20 April 2018; Revised 7 August 2018; Accepted 29 August 2018; Published 30 September 2018

Academic Editor: Mingqiang Li

Copyright ( 2018 Jian-Min Wang et al. This is an open access article distributed under the Creative Commons Attribution License, which permits unrestricted use, distribution, and reproduction in any medium, provided the original work is properly cited.

\begin{abstract}
To study the antioxidant capacity of Astragalus polysaccharides (APS) with different molecular weights, we used hydrogen peroxide to degrade original Astragalus polysaccharide (APS0) with an initial molecular weight of $11.03 \mathrm{kDa}$ and obtained three degraded polysaccharides with molecular weights of 8.38 (APS1), 4.72 (APS2), and $2.60 \mathrm{kDa}$ (APS3). The structures of these polysaccharides were characterized by ${ }^{1} \mathrm{H}$ NMR, ${ }^{13} \mathrm{C}$ NMR, FT-IR, and GC/MS. The degradation process did not cause significant changes in the main chain structure of APS. The monosaccharide component of APS before and after degradation was slightly changed. The antioxidant ability in vitro (removing hydroxyl and ABTS radicals and reducing ability) and in cells (superoxide dismutase and malondialdehyde generation) of these polysaccharides is closely related to their molecular weight. If the molecular weight of APS is very high or low, it is not conducive to their activity. Only APS2 with moderate molecular weight showed the greatest antioxidant activity and ability to repair human kidney epithelial (HK-2) cells. Therefore, APS2 can be used as a potential antistone polysaccharide drug.
\end{abstract}

\section{Introduction}

Radix Astragali is one of the most popular medicinal herbs in China, and it has been used for more than 2000 years. One of its main active ingredients is Astragalus polysaccharides (APS), which show antioxidation, antitumor, and antiaging properties and cardiovascular, liver, and kidney protective effects $[1,2]$.

The polysaccharide property is closely related to its molecular weight, acid group content, monosaccharide composition, glycosidic linkage type, and main chain structure [3-6]. Given the different varieties, qualities, and processing methods, a certain difference exists in its monosaccharide composition and structure [7]. Wang et al. [6] separated APS with a molecular weight of $3.6 \times 10^{4} \mathrm{Da}$ from $\mathrm{A}$. membranaceus roots by hot water extraction method. The main chain of APS is made up of $\alpha-\mathrm{D}-(1 \rightarrow 4)-\mathrm{Glc}$ and $(1 \rightarrow 6)-\alpha-D-G l c p$, and the branching point is located at O-6. Fu et al. [8] obtained APS with a molecular weight of approximately $3.01 \times 10^{5} \mathrm{Da}$ from Mongolian Astragalus using low concentration of ethanol for precipitation and gel chromatography for purification. Spectral analysis results of
${ }^{1} \mathrm{H}$ NMR and ${ }^{13} \mathrm{C}$ NMR showed that the APS backbone has a 1,3-linked $\beta$-D-Gal residue and the branched portion has $\beta$-Glc, 1,6 -linked $\alpha$-Gal; 1,5 -linked $\beta$-Xyl; 1,4 -linked $\beta$-Gal; $\beta$-D-Gal, 1,2-linked $\alpha$-Rha; and 1,2,4-linked $\alpha$-Rha residues.

The molecular weight affects the antioxidant ability of the polysaccharide. In addition, optimal antioxidant ability will vary depending on the type of polysaccharide. Liu et al. [9] reported that Ganoderma lucidum polysaccharide $\left(\mathrm{GLP}_{\mathrm{L}} 1\right)$ with low molecular weight $(5.2 \mathrm{kDa})$ has a higher ability to scavenge free radicals, superoxide radicals, and hydrogen peroxide than the component $\left(\mathrm{GLP}_{\mathrm{L}} 2\right)$ with high molecular weight $(15.4 \mathrm{kDa})$. At a concentration of $10 \mathrm{mg} / \mathrm{mL}$, the scavenging rates of $\mathrm{GLP}_{\mathrm{L}} 1$ to hydroxyl radical and superoxide anion are close to $75 \%$ and $90 \%$, respectively, whereas the scavenging ability of $\mathrm{GLP}_{\mathrm{L}} 2$ is only $50 \%$ and $60 \%$, respectively. Ma et al. [10] isolated four kinds of polysaccharides, namely, GLP1 (>10 kDa), GLP2 $(8-10 \mathrm{kDa})$, GLP3 (2.5$8 \mathrm{kDa})$, and GLP4 $(<2.5 \mathrm{kDa})$, from $\mathrm{G}$. lucidum by ultrasonic method. At the concentration of $0.5 \mathrm{mg} / \mathrm{mL}$, the reducing ability was in the following order: GLP2 > GLP1 > GLP3 > GLP4, showing that the GLP2 polysaccharide with moderate molecular weight had the best reducing ability. Sheng and 
Sun [11] obtained four polysaccharides, namely, CPA-1, CPA-2, CPA-3, and CPA-4, from Athyrium multidentatum (Doll.) Ching by $\mathrm{H}_{2} \mathrm{O}_{2}$ degradation method, and their molecular weights were $14.53,12.37,11.55$, and $6.40 \mathrm{kDa}$, respectively. The DPPH scavenging rates of the four polysaccharides with a concentration of $30 \mu \mathrm{g} / \mathrm{mL}$ were $63.35 \%$, $50.23 \%, 42.45 \%$, and $30.01 \%$, respectively, showing that the polysaccharide with high molecular weight had the greatest scavenging activity.

Free radical-induced oxidative stress is thought to be one of the major causes of kidney disease, including kidney stones [12]. Polysaccharides can remove free radicals in vitro and act as antioxidants to protect living organisms from oxidative damage [13]. Khan [14] certified that free radicals can cause renal epithelial cell damage and allow urine crystals to attach to the damaged epithelial cell layer through simulation of the kidney environment in vitro. This research also proved that renal cell injury induced by free radicals can produce an environment conducive to crystal growth, accelerating the formation of stones. Antioxidant activity means that some antioxidants can protect cells against the damage of reactive oxygen species [15], such as superoxide, singlet oxygen, and hydroxyl radicals. Thus, research and exploring potent natural compounds with antioxidant activities and low cytotoxicity from plants have become very important in the field of biomedicine.

Based on this fact, the effects of the molecular weight of APS on its antioxidant capacity and cell repair ability were studied. The results of this study will provide enlightenment for screening for the optimal active polysaccharides.

\section{Experimental Method}

2.1. Reagents and Instruments. Astragalus polysaccharides (95\% purity) produced by Shaanxi Ciyuan Biology Co. Ltd.; $30 \%$ hydrogen peroxide; anhydrous ethanol; trichloroacetic acid $\left(\mathrm{CCl}_{3} \mathrm{COOH}\right)$; o-phenanthroline; $\mathrm{K}_{4}\left[\mathrm{Fe}(\mathrm{CN})_{6}\right]$; ferrous sulfate $\left(\mathrm{FeSO}_{4} \bullet 7 \mathrm{H}_{2} \mathrm{O}\right)$; potassium bromide $(\mathrm{KBr}) ; \mathrm{D}_{2} \mathrm{O}$ (99.9\%, Sigma); ascorbic acid (Vc); and ferric chloride $\left(\mathrm{FeCl}_{3}\right)$ were all purchased from Guangzhou Chemical Reagent Factory.

Human kidney proximal tubular epithelial (HK-2) cells were purchased from Shanghai Cell Bank, Chinese Academy of Sciences (Shanghai, China). Dulbecco's modified Eagle's medium (DMEM) and fetal bovine serum were purchased from HyClone Biochemical Products Co. Ltd. (UT, USA). Cell culture plates were purchased from Wuxi NEST Biotechnology Co. Ltd. (Wuxi, China). Malondialdehyde (MDA) kit and superoxide dismutase (SOD) kit were purchased from Jiancheng Institute of Biotechnology (China). Hematoxylin-eosin (HE) kit was purchased from Shanghai Beyotime Biotech Co. Ltd. (Shanghai, China).

The apparatus used in this paper were the following: KQ2200DB Ultrasonic Cleaning Instrument (Kunshan Ultrasonic Instruments Co. Ltd.), Ubbelohde capillary viscometer $(0.45 \mathrm{~mm}$, Qihang Glass Instrument Factory, Shanghai, China), conductivity meter (DDS-11A, LEICI, Shanghai, China), ultraviolet-visible spectrophotometer (Cary 500, Varian, Palo Alto, CA, USA), Fourier-transform infrared spectrometer (Equinox 55, Bruker, Karlsruhe, Germany), enzyme mark instrument (Safire2, Tecan, Männedorf, Switzerland), nuclear magnetic resonance (Varian Bruker-600 MHz, Bruker, Germany), 7890A-5975C gas chromatographymass spectrometer (Agilent, USA), and fluorescence microscope (22DI-E-D282, Leica, Solms, Germany).

2.2. Experimental Methods. We followed the methods of Bhadja et al. [16].

2.2.1. Degradation of Polysaccharides. About $1.2 \mathrm{~g}$ original Astragalus polysaccharide (APS0) was weighed and dissolved in $20 \mathrm{~mL}$ distilled water. $\mathrm{H}_{2} \mathrm{O}_{2}$ solution was added to the reaction system $-90^{\circ} \mathrm{C}$ water bath degradation for $2 \mathrm{~h}$. The degradation reaction was cooled at room temperature, at which point the solution $\mathrm{pH}$ was adjusted to 7.0 by adding $2 \mathrm{~mol} / \mathrm{L} \mathrm{NaOH}$ solution. The degraded solution was then concentrated to one-third of its original volume at $60^{\circ} \mathrm{C}$. The product was precipitated by adding three volumes of anhydrous ethanol. After filtration, the degraded polysaccharide was obtained by drying. The above experimental procedure was repeated by changing the $\mathrm{H}_{2} \mathrm{O}_{2}$ concentration at $4 \%, 6 \%$, and $14 \%$; degraded Astragalus polysaccharides with different molecular weights were obtained.

2.2.2. Measurement of Molecular Weights of Polysaccharides. According to the literature [17], the molecular weight was determined by Ubbelohde viscosity method at $25 \pm 0.2^{\circ} \mathrm{C}$. After determining the drop time $T$ of each polysaccharide in the viscometer, the relative viscosity $\eta_{\mathrm{r}}$ and the specific viscosity $\eta_{\mathrm{sp}}$ were calculated, where $\eta_{\mathrm{r}}=T_{\mathrm{i}} / T_{0}$ and $\eta_{\mathrm{sp}}=\eta_{\mathrm{r}}-1$, where $T_{\mathrm{i}}$ and $T_{0}$ are the drop time of polysaccharide solution and deionized water. According to the one-point method, the intrinsic viscosity $[\eta]=\left[2\left(\eta_{\mathrm{sp}}-\ln \eta_{\mathrm{r}}\right)\right]^{1 / 2} / c$, where $c$ is the concentration of the sample to be tested. The molecular weights of each polysaccharide before and after degradation were calculated based on $[\eta]$ values. The relationship between the intrinsic viscosity $[\eta]$ of the polymer solution and the molecular weight $M$ of the polymer can be expressed by the empirical equation of Mark-Houwink: $[\eta]=\kappa M^{\alpha}$, where $\kappa$ and $\alpha$ are the two parameters of the empirical equation and are constants related to polymer morphology, solvent, and temperature.

2.2.3. Analysis of Carboxylic Group Content. The carboxyl group (-COOH) content of APS was measured by conductometric titration. The conductivity titration curve was plotted using the conductivity value as the $Y$-axis and the used $\mathrm{NaOH}$ volume as the $X$-axis. The conductivity titration curve can be divided into three parts, a conductivity reduction stage (A), an equilibrium stage (B), and a conductivity increase stage $(C)$. Three tangent lines are constructed from the three-stage curve, and the intersection is a stoichiometric point. The intersection of lines $\mathrm{A}$ and $\mathrm{B}$ gives the volume of $\mathrm{NaOH}\left(V_{1}\right)$ that excessive $\mathrm{HCl}$ and $-\mathrm{SO}_{3} \mathrm{H}$ consumed; the intersection of lines $\mathrm{B}$ and $\mathrm{C}$ gives the volume of $\mathrm{NaOH}$ $\left(V_{2}\right)$ that excessive $\mathrm{HCl}$ and $-\mathrm{SO}_{3} \mathrm{H}$ and the $-\mathrm{COOH}$ of the APS consumed together; so, $V_{2}-V_{1}$ (platform portion) is the $\mathrm{NaOH}$ volume that the $-\mathrm{COOH}$ of the APS consumed 
alone. The $-\mathrm{COOH}$ content can be obtained according to the following formula [18]:

$$
-\mathrm{COOH}(\%)=\frac{C_{\mathrm{NaOH}} \times\left(V_{2}-V_{1}\right) \times 45 / 1000}{C_{\text {sample }} \times 40 / 1000} \times 100 \text {, }
$$

wherein $C_{\mathrm{NaOH}}(\mathrm{mol} / \mathrm{L})$ represents the molar concentration of $\mathrm{NaOH}, \mathrm{C}_{\text {sample }}(\mathrm{g} / \mathrm{L})$ represents the mass concentration of the polysaccharide, $45 \mathrm{~g} / \mathrm{mol}$ is the molar mass of $-\mathrm{COOH}$, and $40 \mathrm{~mL}$ is the solution volume of polysaccharide. The final value is the average of three parallel experiments.

2.2.4. Fourier-Transform Infrared Spectroscopy (FT-IR) Analysis. A dried polysaccharide sample $(2.0 \mathrm{mg})$ was mixed with $\mathrm{KBr}(200 \mathrm{mg})$. After grinding and pressing into $\mathrm{KBr}$ pellet, scanning was performed between the ranges of $4000 \mathrm{~cm}^{-1}$ to $400 \mathrm{~cm}^{-1}$ with a resolution of $4 \mathrm{~cm}^{-1}$.

2.2.5. ${ }^{1} H N M R$ and ${ }^{13} C N M R$ Detection of APS. According to the literature [19], $20 \mathrm{mg}$ of fully dried APS1 polysaccharides was weighed and added to a NMR tube containing $0.5 \mathrm{~mL}$ of deuterated water $\left(\mathrm{D}_{2} \mathrm{O}\right)$, which is completely dissolved and placed in the magnetic field of the nuclear magnetic resonance spectrometer for detection.

2.2.6. Monosaccharide Component Detection of APS by GCMS. According to the literature [20], $10 \mathrm{mg}$ of APS1 polysaccharide was added to a $121^{\circ} \mathrm{C}$ sealed container containing $2.5 \mathrm{~mol} \cdot \mathrm{L}^{-1}$ trifluoroacetic acid (TFA) $(2 \mathrm{~mL})$ for 90 minutes. The solution was concentrated to dryness under reduced pressure, and then the TFA was removed with $\mathrm{MeOH}$ to a neutral solution and concentrated to dryness under reduced pressure. The residue was dissolved in $2 \mathrm{~mol} / \mathrm{L} \mathrm{NH}_{4} \mathrm{OH}$ $(1 \mathrm{~mL})$ and $1 \mathrm{~mol} \cdot \mathrm{L}^{-1}$ fresh $\mathrm{NaBD}_{4}(1 \mathrm{~mL})$. The reaction was carried out at room temperature for $2.5 \mathrm{~h}$ and stirring was done at room temperature. Then two drops of acetic acid were added to decompose excess $\mathrm{NaBD}_{4}$ until no bubbles were produced. The solution was concentrated to dryness under reduced pressure. The filtrate was added with $\mathrm{MeOH}$ to remove boric acid and dried in vacuo. $1 \mathrm{~mL}$ of acetic anhydride was added and acetylated at $100^{\circ} \mathrm{C}$ for $2.5 \mathrm{~h}$. The acetylated product was extracted with dichloromethane. The organic layer was washed with distilled water, dried, and analyzed by GC-MS. The HP-5MS capillary column $(15 \mathrm{~m} \times 250 \mu \mathrm{m} \times 0.25 \mu \mathrm{m})$ was programmed, and the temperature was raised from $135^{\circ} \mathrm{C}$ to $180^{\circ} \mathrm{C}$ at $0.5^{\circ} \mathrm{C} / \mathrm{min}$, then to $190^{\circ} \mathrm{C}$ at $10^{\circ} \mathrm{C} / \mathrm{min}$, and up to $310^{\circ} \mathrm{C}$ at $40^{\circ} \mathrm{C} / \mathrm{min}$. Helium acts as carrier gas, with a column flow rate of $0.6 \mathrm{~mL} / \mathrm{min}$. The acetylated product was identified by debris ions in GC-MS and relative retention times in GC. The structure is identified by peaks and assessed by peak area. Standard monosaccharides (rhamnose, arabinose, fucose, xylose, mannose, glucose, and galactose) are used as reference.

2.2.7. Hydroxyl Radical $(\bullet \mathrm{OH})$ Scavenging Activity of APS with Different Molecular Weights. The $\bullet \mathrm{OH}$ scavenging ability of polysaccharide in vitro was detected by $\mathrm{H}_{2} \mathrm{O}_{2} / \mathrm{Fe}$ system method [21]. The four different molecular weight polysaccharide solutions $(60 \mu \mathrm{g} / \mathrm{mL}, 1 \mathrm{~mL})$ were incubated with phenanthroline $(2.5 \mathrm{mmol} / \mathrm{L}, 1 \mathrm{~mL})$, ferrous sulfate $(2.5 \mathrm{mmol} / \mathrm{L}, 1 \mathrm{~mL})$, and hydrogen peroxide $(20 \mathrm{mmol} / \mathrm{L}$, $1 \mathrm{~mL})$ in phosphate buffer $(20 \mathrm{mmol} / \mathrm{L}, 1 \mathrm{~mL}, \mathrm{pH} 7.4)$ for $90 \mathrm{~min}$ at $37^{\circ} \mathrm{C}$. The absorbance measured at $536 \mathrm{~nm}$ was designated $A_{1}$. The absorbance when hydrogen peroxide $\left(\mathrm{H}_{2} \mathrm{O}_{2}\right)$ was replaced with distilled water and polysaccharide solution was $A_{2}$ and $A_{3}$, respectively. Ascorbic acid $(\mathrm{Vc})$ was used as the positive control group. The ability to scavenge hydroxyl radicals was calculated using the following equation:

$$
\text { Scavenging effect }(\%)=\frac{\left(A_{3}-A_{1}\right)}{\left(A_{2}-A_{1}\right)} \times 100 \%
$$

2.2.8. ABTS Radical Scavenging Activity of APS with Different Molecular Weights. ABTS was oxidized to produce a stable blue-green cationic radical $\mathrm{ABTS}^{+}$. The antioxidant reacts with $\mathrm{ABTS}^{+}$to cause the reaction to fade and initiate a change in the absorbance of a particular wavelength segment to determine the size of the antioxidant to remove ABTS free radicals [22].

The ABTS radical scavenging activity of polysaccharides was performed according to [23] with slight modification. $7 \mathrm{mmol} / \mathrm{L}$ ABTS solution was mixed with $2.45 \mathrm{mmol} / \mathrm{L}$ potassium persulfate aqueous solution, and then the mixture was incubated in the dark at room temperature for $12-16 \mathrm{~h}$. Then $3 \mathrm{~mL} \mathrm{ABTS}^{+}$solution was added to $1 \mathrm{~mL}$ polysaccharide solutions of various concentrations in a test tube. After reacting for $6 \mathrm{~min}$ at room temperature, the absorbance was measured at $734 \mathrm{~nm}$.

$$
\text { Scavenging effect }(\%)=\left[1-\frac{\left(A_{1}-A_{2}\right)}{A_{0}}\right] \times 100 \% \text {. }
$$

where $A_{0}$ is the control group without polysaccharide, $A_{1}$ is the experiment group, and $A_{2}$ is the blank group without reagents (the absorbance of polysaccharide solution $A_{2}$ was 0$)$.

2.2.9. Reducing Power of APS with Different Molecular Weights. Using the Prussian blue method [24], the polysaccharide sample may reduce the positive $\mathrm{Fe}^{3+}$ ions into $\mathrm{Fe}^{2+}$ ions in potassium ferricyanide $\left(\mathrm{K}_{4}\left[\mathrm{Fe}(\mathrm{CN})_{6}\right]\right)$ to form Prussian blue and develop at $700 \mathrm{~nm}$. That is, the greater the absorbance at $700 \mathrm{~nm}$ is, the stronger is the reduction of polysaccharide [25].

$2 \mathrm{~mL}$ APS with different molecular weights $(60 \mu \mathrm{g} / \mathrm{mL})$ was mixed with $2 \mathrm{~mL}$ phosphate buffer solution (PBS) $(\mathrm{pH}=6.6)$ and $2 \mathrm{~mL} 1 \% \mathrm{~K}_{4}\left[\mathrm{Fe}(\mathrm{CN})_{6}\right]$. The mixture was incubated at $50^{\circ} \mathrm{C}$ for $20 \mathrm{~min} .2 \mathrm{~mL} 10 \%$ trichloroacetic acid was added to the mixture which was then centrifuged for $10 \mathrm{~min}$ at $3000 \mathrm{r} / \mathrm{min}$. The supernatant $(2 \mathrm{~mL})$ was mixed with $0.5 \mathrm{~mL} \mathrm{FeCl}_{3}(0.1 \%, w / v)$ solution and $2 \mathrm{~mL}$ distilled water. The mixture was shaken well and left to stand for $10 \mathrm{~min}$. Then the absorbance was measured at $700 \mathrm{~nm}$. Phosphate buffer was used as negative control, and Vc was used as positive control for comparison. 
TABLE 1: Physicochemical properties and FT-IR characteristic absorption peaks of original and degraded APS.

\begin{tabular}{lccccccccc}
\hline & $\begin{array}{c}\mathrm{H}_{2} \mathrm{O}_{2} \text { concentration } \\
\mathrm{C}_{(\mathrm{H} 2 \mathrm{O} 2)}(\%)\end{array}$ & $\begin{array}{c}\text { Mean molecular } \\
\text { weight (Mr/Da) }\end{array}$ & $\begin{array}{c}\text { - } \mathrm{COOH} \\
\text { content }(\%)\end{array}$ & $\begin{array}{c}\text { Relative intensity } \\
\text { of }-\mathrm{COOH} \\
\text { absorption peak }\end{array}$ & \multicolumn{4}{c}{ Functional group characteristic absorption peak } \\
APS0 & 0 & 11.03 & 16.8 & 1.4 & 3394.8 & 1617.1 & 2927.4 & $1115.5,1087.4,1030.5,763.5$ \\
APS1 & 4 & 8.39 & 16.7 & 1.2 & 3393.7 & 1618.1 & 2931.3 & $1106.1,1082.8,1022.8,764.8$ \\
APS2 & 6 & 4.72 & 17.2 & 1.6 & 3392.7 & 1616.7 & 2932.9 & $1110.8,1081.9,1023.6,762.5$, \\
APS3 & 14 & 2.60 & 16.2 & 1 & 3396.3 & 1622.1 & 2930.8 & $1113.7,1082.1,1027.7,761.9$ \\
\hline
\end{tabular}

* $\left(100-\mathrm{T}_{\mathrm{APS} 0}\right):\left(100-\mathrm{T}_{\mathrm{APS} 1}\right):\left(100-\mathrm{T}_{\mathrm{APS} 2}\right):\left(100-\mathrm{T}_{\mathrm{APS} 3}\right)$, where $\mathrm{T}$ represents the light transmittance.

2.2.10. Cell Culture. HK-2 cells were cultured in DMEM medium containing $10 \%$ fetal bovine serum, $100 \mathrm{U} / \mathrm{mL}$ penicillin, and $100 \mu \mathrm{g} / \mathrm{mL}$ streptomycin antibiotic with a $\mathrm{pH}$ of 7.4 and cultured in a $5 \% \mathrm{CO}_{2}$-humidified environment of $37^{\circ} \mathrm{C}$. Cells were passaged by trypsin digestion. Upon reaching $80 \%-90 \%$ confluent, cells were gently blown after trypsinization to form a cell suspension for the following cell experiments.

\subsubsection{Superoxide Dismutase (SOD) Activity Detection. SOD} activity was assessed using a commercially available kit based on the autooxidation of hydroxylamine. The cell suspension was inoculated in 24-well plates with a cell concentration of $5 \times 10^{4} \mathrm{cell} / \mathrm{mL}$ and $500 \mu \mathrm{L}$ per well and was incubated for $24 \mathrm{~h}$ in an incubator at $37^{\circ} \mathrm{C}$. The experimental model was divided into three groups: (1) control group: only serumfree medium was added, (2) injury group: serum-free medium containing $2.6 \mathrm{mmol} / \mathrm{L}$ oxalate was added for $3.5 \mathrm{~h}$, and (3) repair group: $60 \mu \mathrm{g} / \mathrm{mL}$ of APS solutions with different molecular weights was added to the injured cells and repaired for $10 \mathrm{~h}$. At the indicated time points, the treated cells were homogenized in $100 \mathrm{mmol} / \mathrm{L}$ Tris- $\mathrm{HCl}$ buffer and centrifuged at 10,000 rpm for $20 \mathrm{~min}$ and then the SOD activity was determined using assay kits. The absorbance of the supernatant was then measured directly by a microplate reader at $550 \mathrm{~nm}$ with a reference wavelength of $600 \mathrm{~nm}$.

2.2.12. Malondialdehyde (MDA) Detection. For lipid peroxidation assay, we used a commercial kit to quantify the generation of MDA according to the manufacturer's protocol. Cell culture and polysaccharide treatment were performed using a method similar to that of SOD measurement. After the repair effect was completed, the cells were harvested by trypsinization and cellular extracts were prepared by sonication in ice-cold buffer (50 mM Tris- $\mathrm{HCl}, \mathrm{pH} 7.5,5 \mathrm{mM}$ EDTA, and $1 \mathrm{mM}$ DTT). After sonication, lysed cells were centrifuged at $10000 \mathrm{rpm}$ for $20 \mathrm{~min}$ to remove debris. The supernatant was subjected to the measurement of MDA levels by detecting the absorbance at $532 \mathrm{~nm}$.

2.2.13. Hematoxylin and Eosin (HE) Staining. Cell suspension with a cell concentration of $5 \times 10^{4}$ cells $/ \mathrm{mL}$ was inoculated per well in 12 -well plates, $1 \mathrm{~mL}$ of DMEM containing $10 \%$ fetal bovine serum was added per well, and the cells were incubated for $24 \mathrm{~h}$. Cell culture and polysaccharide treatment were performed using a method similar to that of SOD measurement. After the repair was completed, the supernatant was removed by aspiration and washed 2 times with PBS. Then the cells were fixed with $4 \%$ polyoxymethylene at room temperature for $15 \mathrm{~min}$. After fixation, the cells were stained with hematoxylin stain for 15 minutes. The cells were then washed with distilled water for $2 \mathrm{~min}$ to remove excess stains. Thereafter, the cells were stained with an eosin staining solution for $5 \mathrm{~min}$. The cells were washed with pure water for $2 \mathrm{~min}$ to remove excess eosin. After treatment, the cells were observed under a microscope, the nuclei were stained purple, and the cytoplasm was stained pink.

2.2.14. Statistical Analysis. Experimental data were expressed as mean \pm SD. The experimental results were analyzed statistically using SPSS 13.0 software. The differences of means between the experimental groups and the control group were analyzed by Tukey's test. $p<0.05$ indicates significant difference; $p<0.01$ indicates extremely significant difference.

\section{Results}

3.1. Degradation of APS. Original Astragalus polysaccharide (APS0) with a molecular weight of $11,033 \mathrm{Da}$ was degraded by $\mathrm{H}_{2} \mathrm{O}_{2}$ with concentrations of $4 \%, 6 \%$, and $14 \%$. Three kinds of degraded APS, namely, APS1, APS2, and APS3, with the molecular weights of 8376,4716 , and $2600 \mathrm{Da}$, respectively, were obtained.

3.2. Change in the Contents of the -COOH in APS before and after Degradation. The content of the -COOH in APS was measured by conductivity titration. The results are shown in Table 1. The carboxyl content of three degraded APS was between $16.2 \%$ and $17.2 \%$, which only slightly changed (16.8\%) before degradation.

The carboxyl group content of APS2 (17.2\%) increased slightly. The reason is that hydroxyl radicals produced by the $\mathrm{H}_{2} \mathrm{O}_{2}$ degradation system break the sugar chain, exposing the carboxyl groups. Thus, high levels of carboxyl were detected in polysaccharides with low molecular weight after degradation [26]. Chang et al. [27] degraded the original polysaccharide with a molecular weight of $1.29 \times 10^{2} \mathrm{kDa}$ by ethanol precipitation and obtained two degraded polysaccharides with molecular weights of 60.0 and $52 \mathrm{kDa}$. The content of uronic acid was increased from $70.8 \%$ before degradation to $79.5 \%$ and $86.2 \%$.

The carboxyl group content (16.9\%) of APS3 decreased slightly, probably because free radicals generated by high concentration of $\mathrm{H}_{2} \mathrm{O}_{2}$ (14\%) led to oxidative decarboxylation of 
polysaccharides, allowing the carboxyl groups in the polysaccharide chain to be converted into other groups, such as $-\mathrm{OH}[28]$.

3.3. Structural Characterization of APS by FT-IR Spectra. Figure 1 shows the FT-IR spectra of four APS. The FT-IR spectra of polysaccharides before and after degradation were similar, and no new peaks appeared, which indicated that the degradation of $\mathrm{H}_{2} \mathrm{O}_{2}$ did not cause significant effect on the overall structure of polysaccharides.

The absorption peaks of all four APS are shown in Table 1. The strong absorption band at $3392.7 \mathrm{~cm}^{-1}$ corresponds to the absorption peak of the stretching vibration of $-\mathrm{OH}$ in the polysaccharide. The absorption band at $2932.9 \mathrm{~cm}^{-1}$ corresponds to the stretching vibration of $\mathrm{C}-\mathrm{H}$ [29]. The two distinct absorbance peaks, at about 1616.7 and $1417.9 \mathrm{~cm}^{-1}$, suggested the presence of uronic acids. The absorption peaks at 1113.7 and $1027.7 \mathrm{~cm}^{-1}$ indicate that the polysaccharide contains $\alpha$-glucose residues [30].

As the polysaccharide of each sample has the same mass $(2.0 \mathrm{mg})$, the intensity of the absorption peak can reflect the content of the characteristic functional groups (such as the - $\mathrm{COOH}$ ) [31]. Compared with the original polysaccharide before degradation, the absorption peaks of the $-\mathrm{OH}$ and $-\mathrm{COOH}$ at 3408 and $1620 \mathrm{~cm}^{-1}$ were enhanced and the peaks of APS2 were the strongest, which was probably due to the exposure of the $-\mathrm{OH}$ and $-\mathrm{COOH}$ of polysaccharides after degradation, thus increasing their content $[32,33]$. The intensity change of the absorption peak of the $-\mathrm{COOH}$ is consistent with the change rule of the measured content of the $-\mathrm{COOH}$ (Table 1).

3.4. Structural Analysis of APS by ${ }^{1} H N M R$ and ${ }^{13} C$ NMR. The polysaccharides were characterized by ${ }^{1} \mathrm{H}$ and ${ }^{13} \mathrm{C}$ NMR spectroscopy and typical spectra are shown in Figure 2.

3.4.1. ${ }^{1} H$ NMR. Table 2 lists the attribution of each line in the ${ }^{1} \mathrm{H}$ NMR spectra of APS1 and APS2. The ${ }^{1} \mathrm{H}$ NMR spectrum of APS1 was similar to that of APS2 (Table 2). For APS2, the signal peaks at $\delta 5.31$ and $\delta 4.87 \mathrm{ppm}$ correspond to the chemical shifts of H-1 of $(1 \rightarrow 4)-\alpha-\mathrm{D}-\mathrm{Glcp}$ and $(1 \rightarrow 6)-\alpha-\mathrm{D}-\mathrm{Glcp}$, respectively. The highly overlapping peak at $\delta 3.42-3.88 \mathrm{ppm}$ belongs to the $\mathrm{H}-2, \mathrm{H}-3, \mathrm{H}-4$, $\mathrm{H}-5$, and H-6 signals of $(1 \rightarrow 4)-\alpha-\mathrm{D}-\mathrm{Glcp}$ and $(1 \rightarrow 6)-\alpha-D-G l c p$ of polysaccharides [34]. The proton signals at $\delta 5.12$ and $5.08 \mathrm{ppm}$ belong to the $\mathrm{H}-1$ signal of $(1 \rightarrow 6)-\alpha-D-G a l$ and $(1 \rightarrow)-\alpha-D-R h a$, respectively, of polysaccharide.

3.4.2. ${ }^{13} \mathrm{C}$ NMR Spectrum. Table 3 lists the attribution of the lines in the ${ }^{13} \mathrm{C}$ NMR spectra of APS1 and APS2. The ${ }^{13} \mathrm{C}$ NMR spectrum of APS1 was similar to that of APS2. For APS2, the signal at $\delta 103.7 \mathrm{ppm}$ belongs to the $\mathrm{C}-1$ signal peak of $\beta-\mathrm{D}-\mathrm{Glcp}$ of polysaccharide. The signals at $\delta 99.6, \delta 71.5$, $\delta 73.2, \delta 76.7, \delta 71.2$, and $\delta 60.4 \mathrm{ppm}$ are attributed to $\mathrm{C}-1$, C-2, C-3, C-4, C-5, and C-6 signals of $(1 \rightarrow 4)-\alpha-\mathrm{D}-\mathrm{Glcp}$, respectively. The signals at $\delta 71.9, \delta 73.1, \delta 69.3, \delta 70.4$, and $\delta 65.6 \mathrm{ppm}$ are attributed to C-2, C-3, C-4, C-5, and C6 signals of $(1 \rightarrow 6)-\alpha-D-G l c p$, respectively $[34,35]$. The signals at $\delta 100.2, \delta 72.7, \delta 72.3, \delta 81.2$, and $\delta 73.3 \mathrm{ppm}$ are

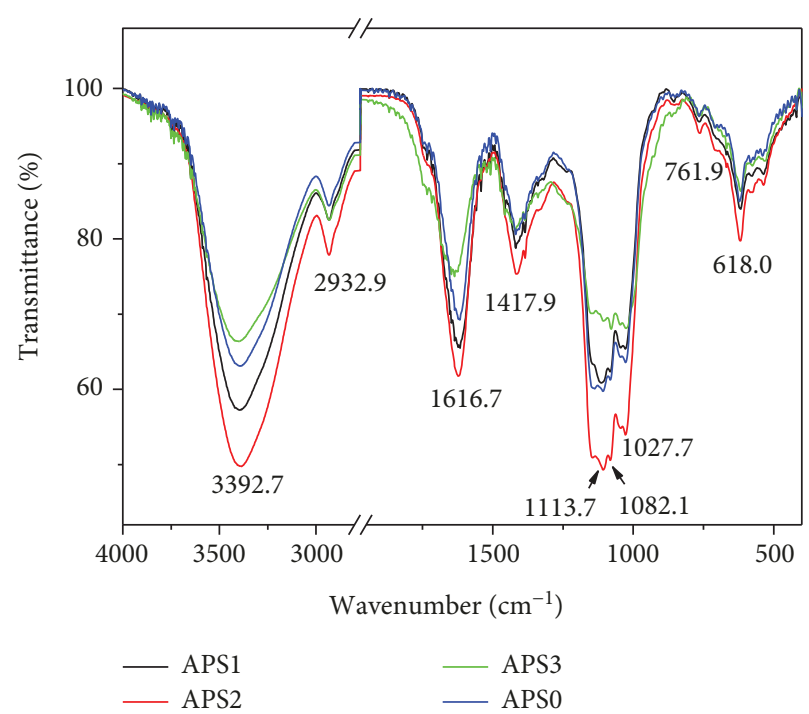

FIGURE 1: Infrared spectrum of APS with different molecular weights.

attributed to C-1, C-2, C-3, C-4, and C-5 signal peaks of $(1 \rightarrow 4)-G a l A$, respectively [36]. The signals at $\delta 92.1$, $\delta 72.2, \delta 70.1, \delta 83.7$, and $\delta 69.0 \mathrm{ppm}$ correspond to the C-1, C$2, \mathrm{C}-3, \mathrm{C}-4$, and C-5 signal peaks of $(1 \rightarrow)-\alpha-\mathrm{D}-\mathrm{Rha}$, respectively. The signals at $\delta 70.5, \delta 72.4$, and $\delta 63.7 \mathrm{ppm}$ are attributed to the C-4, C-5, and C-6 signal peaks of $(1 \rightarrow 6)-\alpha-\mathrm{D}-$ Gal, respectively.

3.5. Monosaccharide Composition of APS. The GC spectra of APS1, APS2, APS3, and 7 standard monosaccharides after derivatization were obtained by GC-MS, as shown in Figure 3. The retention time of each monosaccharide peak in APS is consistent with the retention time of standard monosaccharides of glucose, arabinose, rhamnose, and galactose (Figure 3(a)). According to the peak area, the molar ratio of monosaccharides in APS1 can be calculated as 11.4:7.8:0.7:1 (Figure 3(b)). The molar ratio of monosaccharides in APS2 is 13.9:8.2:1.2:1 (Figure 3(c)). The molar ratio of monosaccharides in APS3 is $13.3: 8.4: 1.1: 1$ (Figure 3(d)).

3.6. Differences in Scavenging Capacity of $\bullet \mathrm{OH}$ Radicals of Polysaccharides with Different Molecular Weights. Among the reactive oxygen free radicals in the body, hydroxyl radicals $(\bullet \mathrm{OH})$ are known as the strongest oxidants, which can induce damage of surrounding biological macromolecules, such as certain proteins, nucleic acids, and unsaturated fatty acids. Such injuries can cause aging, cancer, and other diseases [37].

The $\bullet \mathrm{OH}$ scavenging capacity of the four kinds of APS is shown in Figure 4. The $\bullet \mathrm{OH}$ scavenging rate increased with the increase in APS concentration from $0.15 \mathrm{mg} / \mathrm{mL}$ to $3 \mathrm{mg} / \mathrm{mL}$. The $\mathrm{IC}_{50}$ of APS0, APS1, APS2, APS3, and the positive control group $(\mathrm{Vc})$ were $3.1,2.7,2.4,4.2$, and $0.06 \mathrm{mg} / \mathrm{mL}$, respectively, which indicated that all APS had the ability to remove $\bullet \mathrm{OH}$ radicals and APS2 with moderate molecular weight had the strongest scavenging 


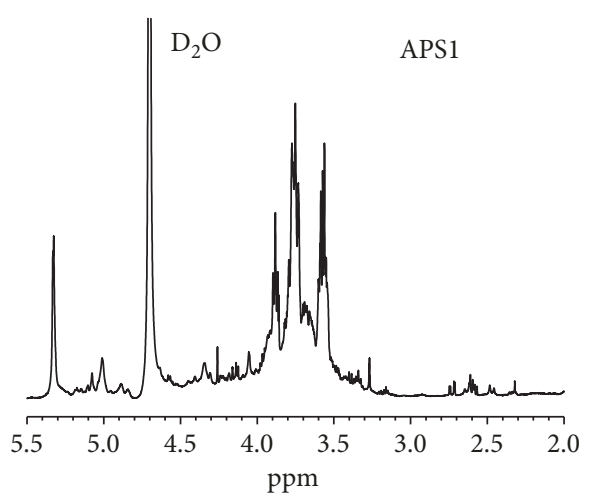

(a)

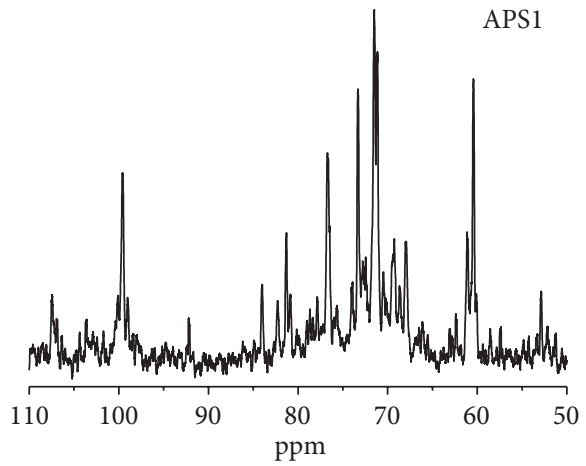

(c)

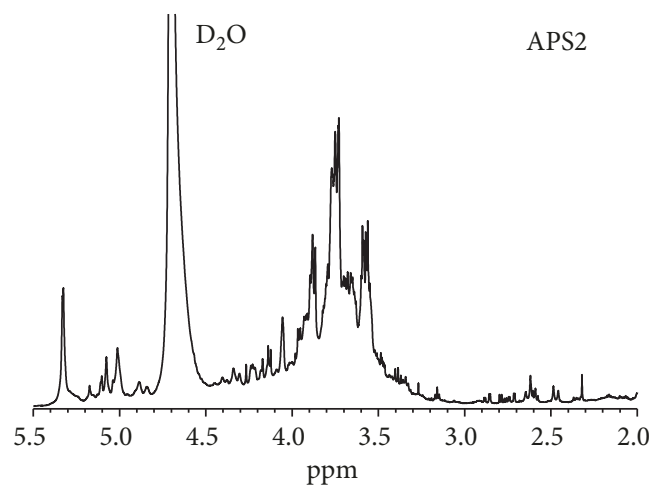

(b)

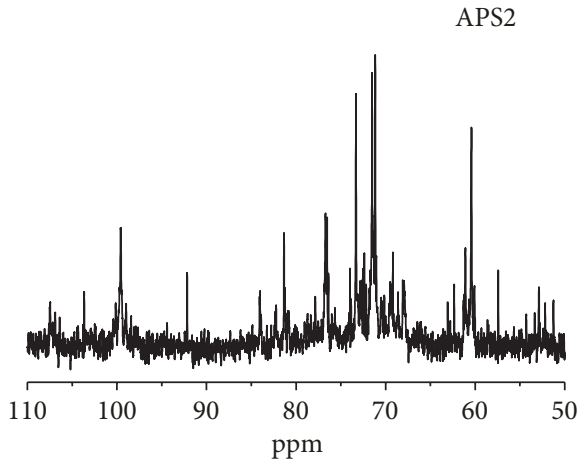

(d)

Figure 2: Nuclear magnetic resonance spectra of APS1 and APS2. (a) ${ }^{1} \mathrm{H}$ NMR spectrum of APS1; (b) ${ }^{1} \mathrm{H}$ NMR spectrum of APS2; (c) ${ }^{13} \mathrm{C}$ NMR spectrum of APS1; (d) ${ }^{13} \mathrm{C}$ NMR spectrum of APS2.

TABLE 2: Structure characterization of APS1 and APS2 by ${ }^{1} \mathrm{H}$ NMR spectra.

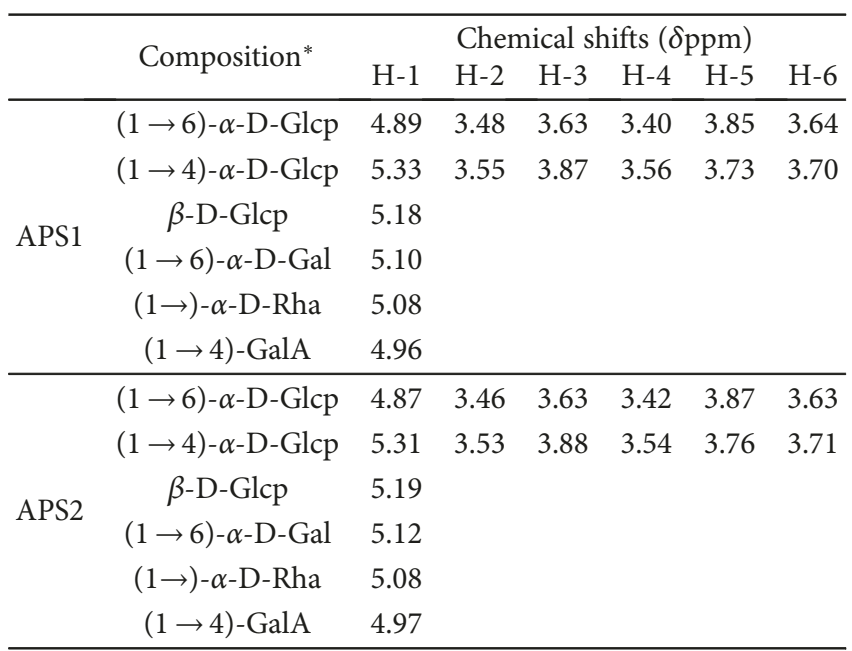

*Gal: galactose; Glcp: glucose; Rha: rhamnose; GalA: glucuronic acid.

capacity. At a concentration of $2.5 \mathrm{mg} / \mathrm{mL}$, the scavenging rate of APS2 (63.4\%) was twice as high as that of APS3 $(31.7 \%)$ with the lowest molecular weight and it was also obviously higher than that of APS0 (45.3\%) with the highest molecular weight. However, the scavenging rates of the four polysaccharides were all less than that of $\mathrm{Vc}(97.8 \%)$.
TABLE 3: Structure characterization of APS1 and APS2 by ${ }^{13} \mathrm{C}$ NMR spectra.

\begin{tabular}{cccccccc}
\hline \multirow{2}{*}{ Composition* $^{*}$} & \multicolumn{6}{c}{ Chemical shifts $(\delta p p m)$} \\
& C-1 & C-2 & C-3 & C-4 & C-5 & C-6 \\
\hline$\beta$-D-Glcp & 103.6 & & & & & \\
& $(1 \rightarrow 4)-\alpha$-D-Glcp & 99.6 & 71.5 & 73.3 & 76.7 & 71.1 & 60.4 \\
APS1 & $(1 \rightarrow 4)$-GalA & 100.1 & 72.6 & 72.4 & 81.3 & 73.3 & \\
& $(1 \rightarrow 6)-\alpha$-D-Glcp & & 71.8 & 73.0 & 69.3 & 70.4 & 65.7 \\
& $(1 \rightarrow)-\alpha$-D-Rha & 92.2 & 72.3 & 70.1 & 83.7 & 69.0 & \\
& $(1 \rightarrow 6)-\alpha$-D-Gal & & & & 70.5 & 72.4 & 63.6 \\
\hline \multirow{4}{*}{$\beta-\mathrm{D}-\mathrm{Glcp}$} & 103.7 & & & & & \\
& $(1 \rightarrow 4)-\alpha$-D-Glcp & 99.6 & 71.5 & 73.2 & 76.7 & 71.2 & 60.4 \\
APS2 & $(1 \rightarrow 4)-$ GalA & 100.2 & 72.7 & 72.3 & 81.2 & 73.3 & \\
& $(1 \rightarrow 6)-\alpha$-D-Glcp & & 71.9 & 73.1 & 69.3 & 70.4 & 65.6 \\
& $(1 \rightarrow)-\alpha$-D-Rha & 92.1 & 72.2 & 70.1 & 83.7 & 69.0 & \\
& $(1 \rightarrow 6)-\alpha$-D-Gal & & & & 70.5 & 72.4 & 63.7 \\
\hline
\end{tabular}

*Gal: galactose; Glcp: glucose; Rha: rhamnose; GalA: glucuronic acid.

3.7. Differences of ABTS Radical Scavenging Capacity of APS with Different Molecular Weights. Four kinds of APS with different molecular weights all had an obvious scavenging effect on ABTS free radicals (Figure 5) and showed a dosedependent relationship in the concentration range of $0.15-$ $3 \mathrm{mg} / \mathrm{mL}$. At the concentration of $2.5 \mathrm{mg} / \mathrm{mL}$, the scavenging 


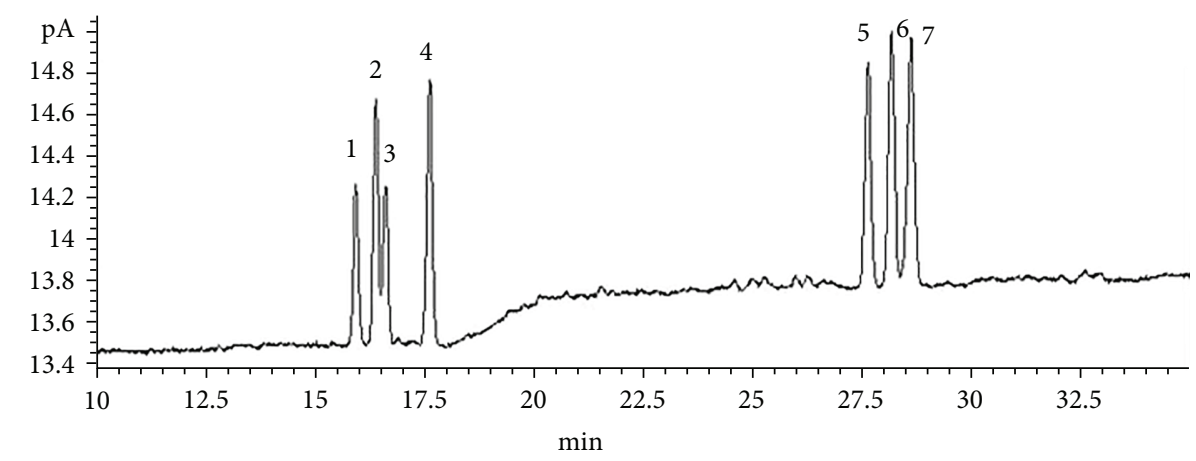

(a)

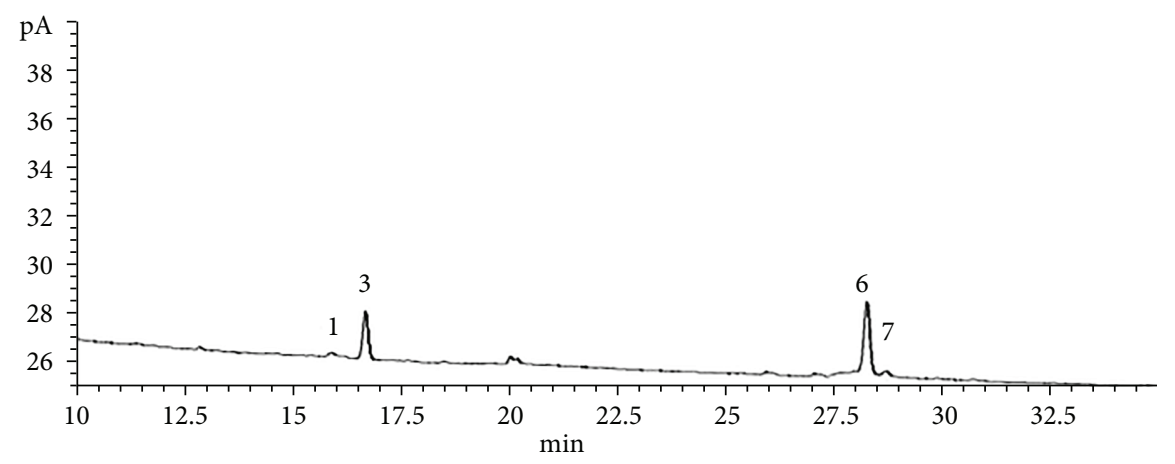

(b)

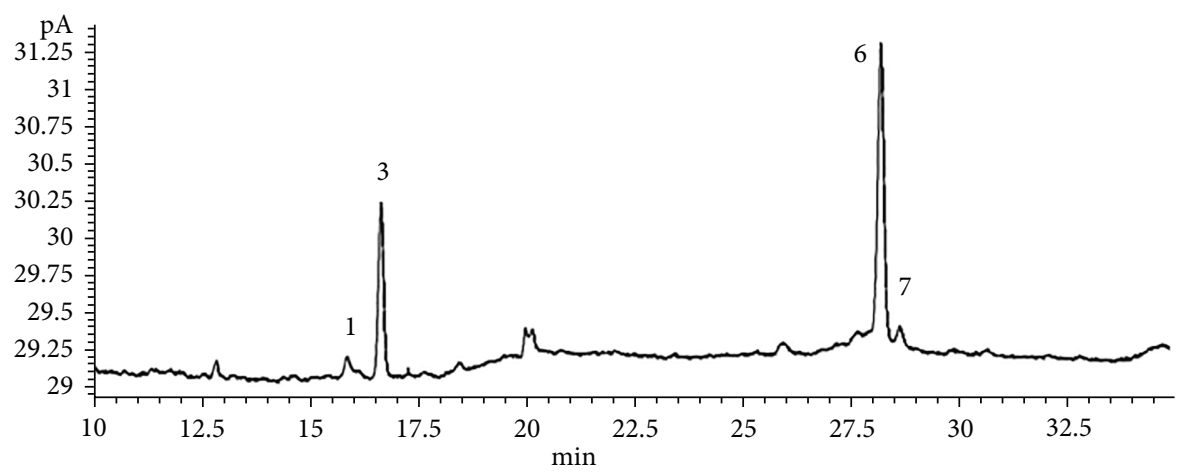

(c)

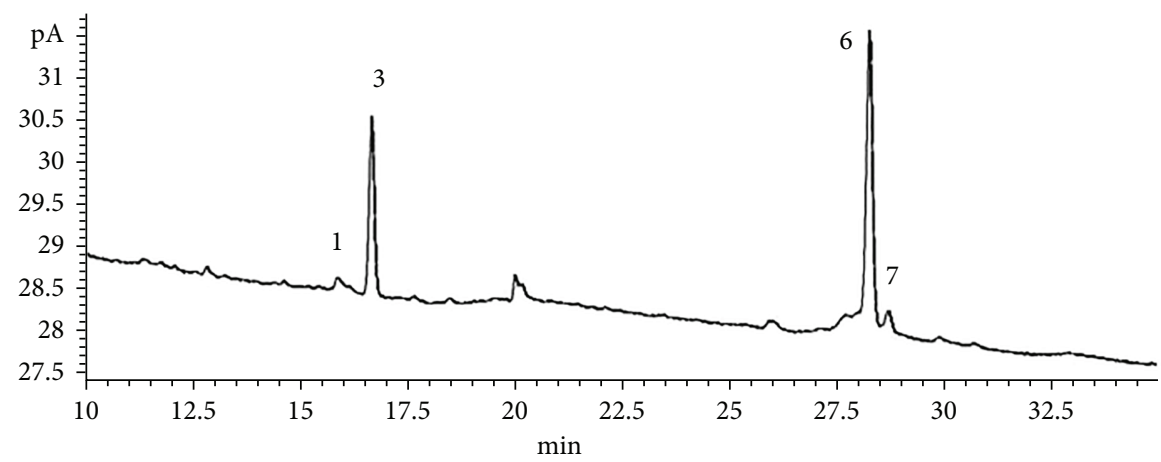

(d)

FIGURE 3: Gas chromatography-mass spectrometry (GC-MS) results of APS. (a) Gas chromatogram of standard monosaccharides. (b) Monosaccharide component of APS1. (c) Monosaccharide component of APS2. (d) Monosaccharide component of APS3. 1: rhamnose; 2: fucose; 3: arabinose; 4: xylose; 5: mannose; 6: glucose; 7: galactose. 


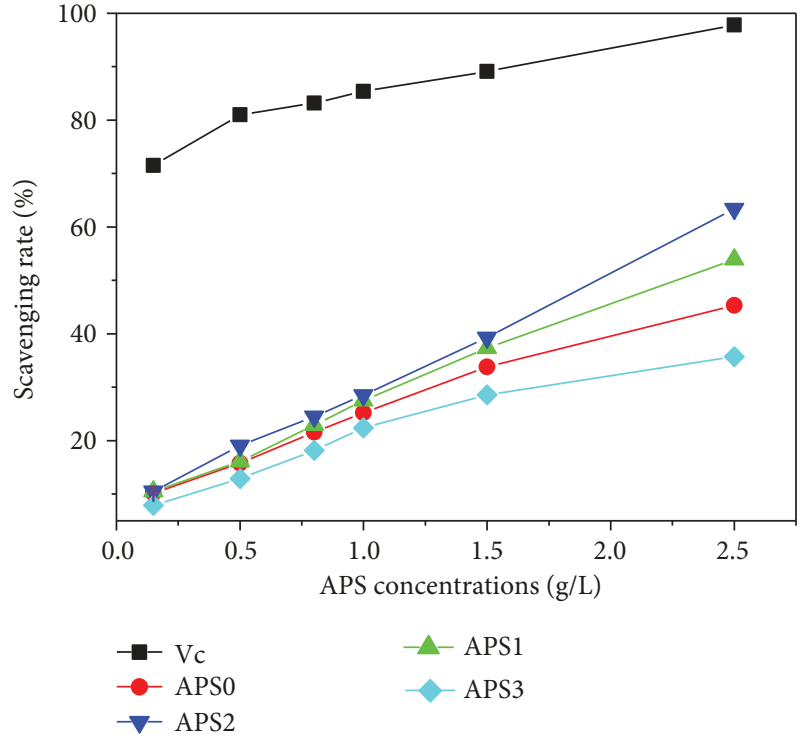

FIGURE 4: Hydroxyl radical scavenging capacity of APS with different molecular weights.

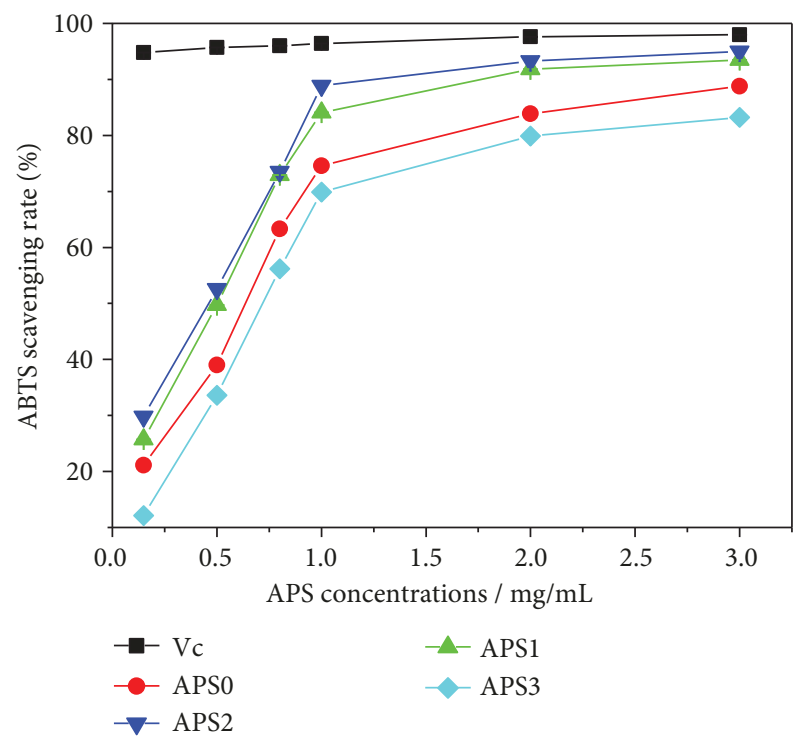

FIGURE 5: ABTS radical scavenging capacity of APS with different molecular weights.

rates of APS0, APS1, APS2, and APS3 were 88.8\%, 93.5\%, $95 \%$, and $83.2 \%$, respectively, which indicated that APS2 with moderate molecular weight had the highest antioxidant activity and was slightly lower than Vc (98\%).

3.8. Differences of Reducing Ability of APS with Different Molecular Weights. The reducing ability of materials in vivo provides hydrogen atoms to destroy the free radical reaction chain, so as to achieve antioxidation. Therefore, the reducing ability is an important indicator of the potential antioxidant capacity of antioxidants.

As shown in Figure 6, the reducing ability of each polysaccharide showed a concentration-dependent manner.

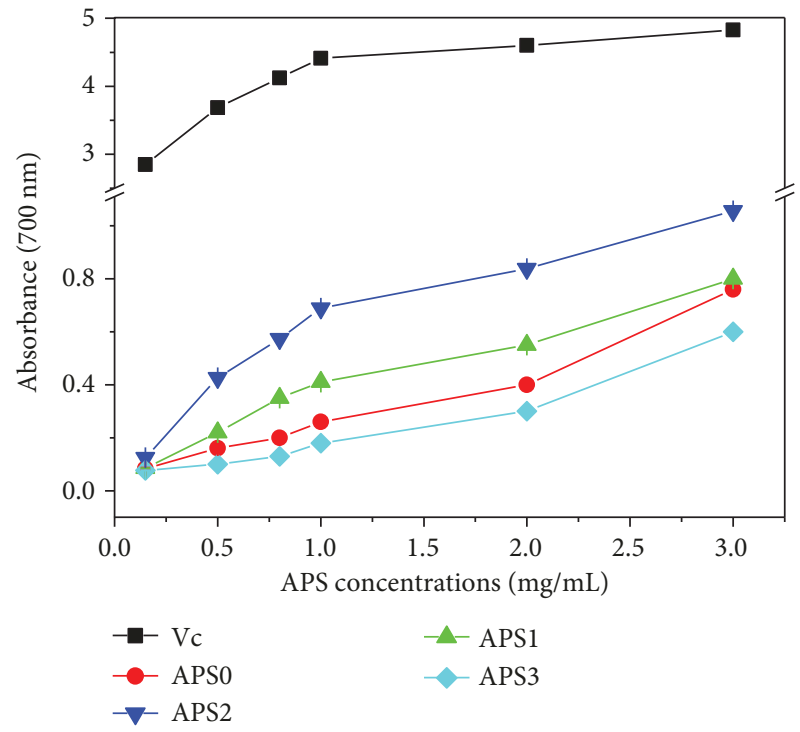

FIGURE 6: Reducing power of APS with different molecular weights.

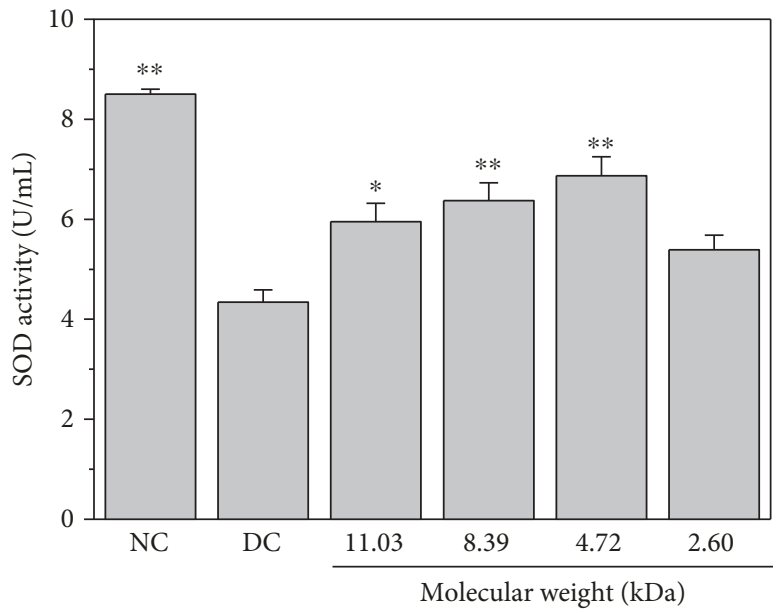

FIGURE 7: Changes of SOD activity after the damaged HK-2 cells were repaired by APS with different molecular weights for $10 \mathrm{~h}$. NC: normal control; DC: damaged control. Compared with the DC group, $*$ indicates $p<0.05 . * *$ indicates $p<0.01$.

When the concentration was $2.5 \mathrm{mg} / \mathrm{mL}$, the ability of the four polysaccharides to reduce $\mathrm{Fe}^{3+}$ was in the following order: APS2 (1.06) > APS1 (0.8) > APS0 (0.76) > APS3 (0.6). APS2 had the highest reducing ability.

3.9. Changes of SOD Activity in Damaged Cells and APSRepaired Cells. The reduction of SOD activity in organism implies decreased ability to resist free radical-induced damage in organism [38]. Figure 7 shows the changes of SOD activity in damaged HK-2 cells after polysaccharide repair for $10 \mathrm{~h}$. It can be seen that the activity of intracellular SOD increases first and then decreases with the decrease of APS molecular weight. The SOD activity in the control group was $8.5 \pm 0.1 \mathrm{U} / \mathrm{mL}$, and it decreased to $4.34 \pm 0.25 \mathrm{U} / \mathrm{mL}$ after $2.6 \mathrm{mmol} / \mathrm{L}$ oxalate damage. After 


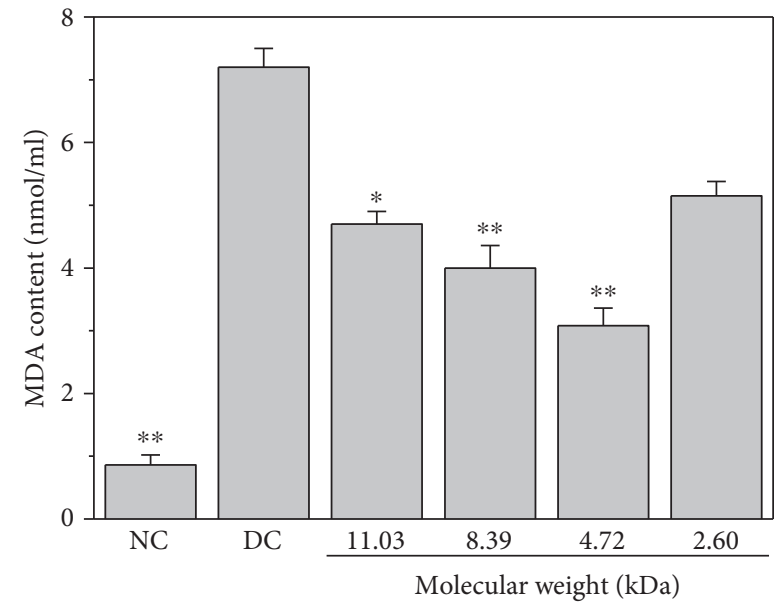

FIGURE 8: Changes of MDA content after the damaged HK-2 cells were repaired by APS with different molecular weights for $10 \mathrm{~h}$. NC: normal control; DC: damaged control. Compared with the DC group, $*$ indicates $p<0.05 . * *$ indicates $p<0.01$.

damaged cells were repaired by APS0, APS1, APS2, and APS3 for $10 \mathrm{~h}$, the SOD activity increased to $5.95 \pm 0.38$, $6.3 \pm 0.36,6.87 \pm 0.37$, and $5.39 \pm 0.29 \mathrm{U} / \mathrm{mL}$, respectively. APS2 with moderate molecular weight has the strongest ability to enhance SOD activity.

3.10. Changes of MDA Content in Damaged Cells and APSRepaired Cells. The change of MDA content usually reveals the level of lipid peroxidation in vivo and indirectly reflects the degree of cell injury [39]. After the cells were injured by $2.6 \mathrm{mmol} / \mathrm{L}$ oxalate, the release of MDA increased from $0.86 \pm 0.16 \mathrm{nmol} / \mathrm{mL}$ (control group) to $7.2 \pm 0.3 \mathrm{nmol} / \mathrm{mL}$ (Figure 8), indicating that HK-2 cells suffered oxidative damage. When the damaged cells were repaired by APS0, APS1, APS2, and APS3 for $10 \mathrm{~h}$, the generation content of MDA decreased from $7.2 \pm 0.3 \mathrm{nmol} / \mathrm{mL}$ to $4.7 \pm 0.3,4.0 \pm 0.3$, $3.08 \pm 0.28$, and $5.15 \pm 0.23 \mathrm{nmol} / \mathrm{mL}$, respectively. That is, APS inhibit the release of MDA to the outside of the cells. Especially, APS2 with moderate molecular weight has the strongest ability to inhibit MDA release.

3.11. Cell Morphology Repair of APS with Different Molecular Weights in HK-2 Cells. The morphological changes of renal proximal tubule epithelial cells (HK-2) after repair by APS with different molecular weights were observed by hematoxylin and eosin staining (Figure 9). Normal HK-2 grows tightly and is plump. After oxidative damage by $2.6 \mathrm{mmol} / \mathrm{L}$ oxalic acid, the inherent form of HK-2 cells was lost. The cell volume was reduced, and nuclei staining was enhanced. Many dense apoptotic bodies were formed. After repair in injured HK-2 cells by APS with different molecular weights, the cell number increased and the cell morphology recovered similar to normal cells in varying degrees. Especially for the APS2-repaired cells, the morphology is the closest to normal cells. By contrast, APS3 with a lower molecular weight and APSO with a higher molecular weight were less effective than APS2.

\section{Discussion}

4.1. Chemical Structure of APS. The structure of polysaccharides is the basis for their biological activity. Many factors affect the biological activity of polysaccharides, including molecular weight, acid group content, monosaccharide composition, ligand type, and main chain structure [3-6]. In the present study, the monosaccharide composition and type of sugar residues of APS were analyzed by ${ }^{1} \mathrm{H}$ NMR, ${ }^{13} \mathrm{C}$ NMR, GC-MS, and FT-IR spectroscopy.

From the results of comprehensive analysis (Figures 1-3), $\alpha$-and $\beta$-glycosidic bonds exist in the four kinds of APS. The main structure is that the main chain is composed of $(1 \rightarrow 4)$ connected Glcp and the branch point is located at the C-6 position of $(1 \rightarrow 6)$ connected Glcp, both containing 1,4linked glucuronic acid fragments (Figure 10). The main structure is basically consistent with the structure illustrated by $\mathrm{Li}$ and Zhang [29]. Fu et al. [8] also found that APS mainly consist of glucose, rhamnose, xylose, and galactose, which is inconsistent with our results in that the monosaccharides of APS consisted of rhamnose, arabinose, fucose, sugar, mannose, glucose, and galactose. Even with the same species of polysaccharides, differences will exist in their monosaccharide components due to their origin, processing method, separation process, and purification conditions [27].

The main chain structures of the four polysaccharides were similar from FT-IR results (Figure 1), but the absorption peak intensities of characteristic functional group of the polysaccharides before and after degradation were different (Table 1). This finding is mainly because the hydroxyl radicals produced by $\mathrm{H}_{2} \mathrm{O}_{2}$ degradation can attack the polysaccharide glycosidic bonds and cleave them, resulting in the change of side chain structure but not the main chain structure in polysaccharides. For example, Tian et al. [40] analyzed the chitosan structure before and after $\mathrm{H}_{2} \mathrm{O}_{2}$ degradation by infrared spectroscopy and nuclear magnetic resonance. The depolymerization only leads to changes of side groups, and no distinct change takes place in the structures of the main chain.

\subsection{Effects of Molecular Weight on the Activity of APS Polysaccharides}

4.2.1. Reasons for the Low Activity in Low-Molecular Weight APS. For different types of plant polysaccharides, the range of molecular weights that exhibit the best bioactivity is different. When the molecular weight of APS is very low, an active polymeric structure might not form, resulting in the loss of polysaccharide activity [41]. In low-molecular weight polysaccharide, the unique bond linking method of polysaccharide and their three-dimensional structure (conformation) based on intramolecular hydrogen bond of polysaccharide will be destructed. The carbonyl group in low-molecular weight polysaccharide changed to be in an open chain, whereas in high-molecular weight polysaccharide, it was attached to a ring molecule. The destruction of the ring structure will break the hydrogen bond structure of the polysaccharide molecule, leading to reduced bioactivity. 


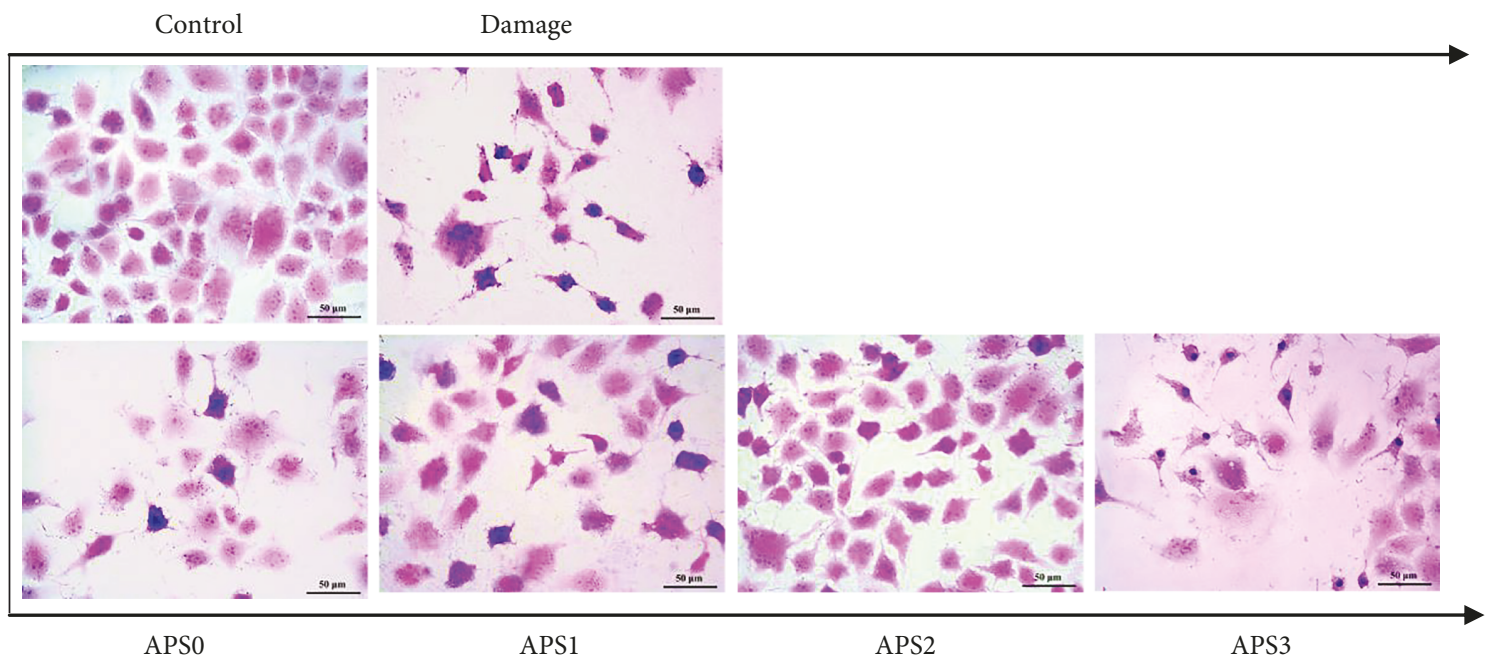

FIgURE 9: Morphological changes after the damaged HK-2 cells were repaired by APS with different molecular weights. Oxalic acid concentration: $2.6 \mathrm{mmol} / \mathrm{L}$, injury time: $3.5 \mathrm{~h}$; polysaccharide concentration: $60 \mu \mathrm{g} / \mathrm{mL}$, repair time: $10 \mathrm{~h}$.

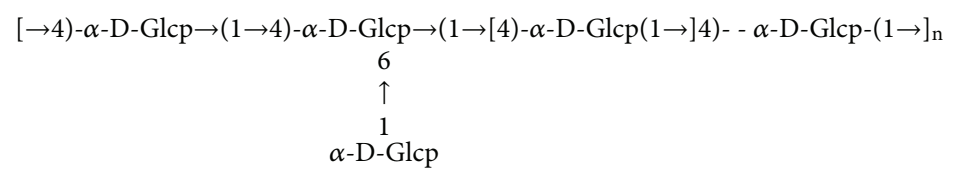

(a)

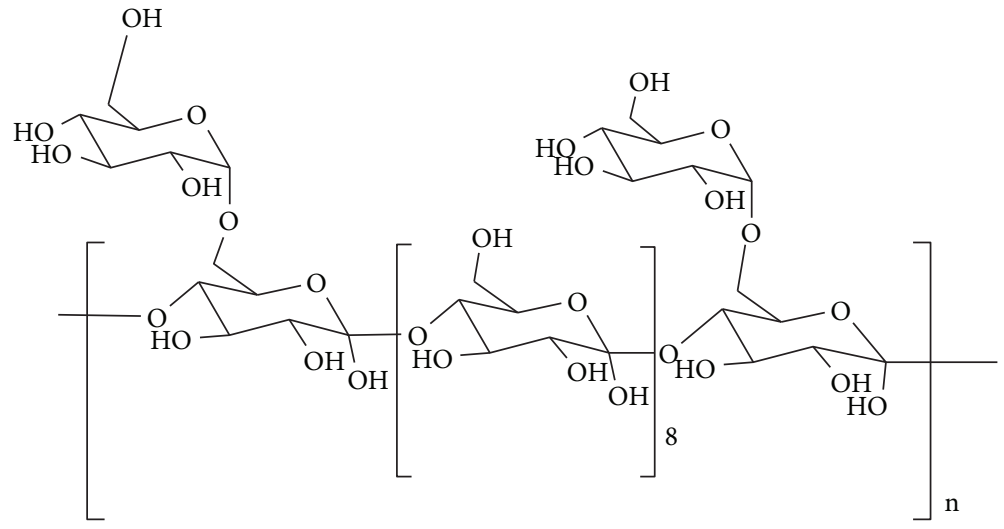

(b)

Figure 10: Molecular structure of APS. (a) Chain structure; (b) skeleton structure.

Polysaccharide has two mechanisms of clearing the hydroxyl radical: the first is to remove the alreadygenerated hydroxyl radicals and the second is to inhibit the generation of hydroxyl radicals [42]. The former mechanism is related to that hydroxyl radical can quickly capture the hydrogen atom of the $\mathrm{C}-\mathrm{H}$ chain of polysaccharide and form $\mathrm{H}_{2} \mathrm{O}$, whereas, the carbon atom of polysaccharide generates a single electron and turns into carbon free radical which then will be oxidized to be a peroxy radical that decomposes harmless products to organism [43]. The latter mechanism is related to the transition of metal ions that catalyze the generation of hydroxyl radicals, so the chelating ability may affect the hydroxyl radicals [44].

Hydroxyl radical can quickly capture the hydrogen atom of the C-H chain of polysaccharide and form $\mathrm{H}_{2} \mathrm{O}$ [43]. In addition, the acid group of polysaccharide (such as - $\mathrm{COOH}$ ) can decrease the production of hydroxyl radicals through the inactivating Fenton reaction. The carboxyl group content has considerable effect on scavenging $\bullet \mathrm{OH}$ radicals [45]. APS contained many hydroxyl groups and carboxyl groups in each monomer unit. Polysaccharides with low molecular weights would have more reductive hydroxyl group or carboxyl group terminals (on per unit mass basis) to accept and eliminate the free radicals [46]. The chain structure of APS3 with the lowest molecular weight suffered significant destruction, and its molecular structure was the most loose. Therefore, the ability of APS3 to clear free radicals was the lowest. Chen et al. [47] reported that when the hydroxyl groups from polysaccharide are replaced with sulfuric acid groups, the antioxidant activity of polysaccharides decreases, 
which also indicates that the reduction in the number of hydroxyl groups will reduce the antioxidant activity of polysaccharides. Lai et al. [48] extracted two molecular weights of mung bean polysaccharides by ethanol precipitation. At a concentration of $0.8 \mathrm{mg} / \mathrm{mL}$, the DPPH free radical scavenging rate $(70.2 \%)$ of mung bean polysaccharide with low molecular weight $(45 \mathrm{kDa})$ was weaker than that of mung bean polysaccharide $(91.6 \%)$ with high molecular weight $(83 \mathrm{kDa})$.

4.2.2. Reasons for the Low Activity in High-Molecular Weight APS. APS0 has high molecular weight, molecular volume, and viscosity and relatively low solubility, which affect its biological activity. The biological activity of polysaccharides is closely related to the single-helix structure of the main chain and hydrophilic group (hydroxyl group) located on the surface of the spirochetes [49]. Another reason is because the polysaccharide with high molecular weight has a more compact structure and stronger intramolecular hydrogen bonds, resulting in less exposure of effective active groups. Qi et al. [50] found that the polysaccharide chain has a reduction and a nonreducing end. The greater the molecular weight of polysaccharides is, the lesser the reduction and nonreducing end contents are and the weaker the antioxidant activity is.

Polysaccharide degradation can effectively improve its antioxidant capacity. After degradation of APS0 to the polysaccharide with a suitable molecular weight, the branching degree of the polysaccharide becomes small, providing sufficient spatial extent to form a regular helical structure, which favors the exposure of more hydroxyl groups to the surface of the helical structure and is good for exerting bioactivity.

For example, Lycium barbarum polysaccharides with low molecular weight $(10.2 \mathrm{kDa})$ have anticancer activity, whereas those with high molecular weight $\left(6.50 \times 10^{3} \mathrm{kDa}\right)$ have no anticancer activity [51]. Similarly, Ligusticum chuanxiong polysaccharide with low molecular weight has a strong reducing ability [52]. At a concentration of $5 \mathrm{mg} / \mathrm{mL}$, the $\mathrm{IC}_{50}$ values of reduction capacity of three kinds of Rhizoma chuanxiong polysaccharides with molecular weights of $2.83 \times 10^{4}, 1.23 \times 10^{4}$, and $6.31 \times 10^{4} \mathrm{Da}$ are $1.05,1.1$, and $0.84 \mathrm{mg} / \mathrm{mL}$, respectively. However, the immunoregulatory effect of Opuntia polysaccharides with high molecular weight $(133 \mathrm{kDa})$ on macrophages is better than that of Opuntia polysaccharides with low molecular weight (168 kDa) [53].

4.2.3. APS with Moderate Molecular Weight Has the Strongest Activity. As shown in Figures 4-6, the antioxidant capacity of APS was in the following order: APS $2>$ APS $1>$ APS0 $>$ APS3, and APS2 had the strongest antioxidant capacity. APS with a very high (APS0) or low (APS3) molecular weight had weakened antioxidant capacity. The ability of each polysaccharide to repair damaged HK-2 cells also showed the same activity sequence.

A number of studies have also confirmed that polysaccharides with moderate molecular weight have more conducive activity $[54,55]$. For example, Im et al. [54] studied the immunomodulatory and antitumor functions of aloe polysaccharides with different molecular weights. The results showed that the inhibitory rate of aloe polysaccharide G2E1DS2 (Mw $=5-400 \mathrm{kDa})$ with moderate molecular weight on the growth of S180 cells in mice was $91.53 \%$. The inhibition rates of G2E1DS3 $(>400 \mathrm{kDa})$ with the highest molecular weight and G2E1DS1 $(<5 \mathrm{kDa})$ with the lowest molecular weight were only $14.87 \%$ and $15.89 \%$, respectively. Fan et al. [55] isolated three polysaccharides (DDP1, DDP2, and DDP3) with molecular weights of 51.5, 26.1, and $6.95 \mathrm{kDa}$, respectively, from Dendrobium denneanum by hot water extraction. At the concentration of $2 \mathrm{mg} / \mathrm{mL}$, the scavenging ability of the three polysaccharides to $\bullet \mathrm{OH}$, $\mathrm{DPPH}$, and ABTS radicals was in the following order: DDP2 $>$ DDP1 > DDP3. Moreover, the antioxidant capacity of DDP2 with moderate molecular weight $(26.1 \mathrm{kDa})$ was the strongest.

Chen et al. [5] obtained three kinds of APS, namely, APS1-1, APS2-2, and APS3-3, by DEAE resin column chromatography, with molecular weights of 112, 98.3, and $20.4 \mathrm{kDa}$, respectively, and with the uronic acids content of $0.0 \%, 5.9 \%, 11.6 \%$, respectively. Their corresponding total antioxidant capacities were 1152.8, 1566.3, and $1580.4 \mu \mathrm{mol} / \mathrm{L}$, respectively, at the concentration of $2 \mathrm{mg} /$ $\mathrm{mL}$. These findings showed that polysaccharides with a high uronic acid content and a low molecular weight have great antioxidant ability. There are two variables (molecular weight and uronic acid content) in this study, and it is difficult to determine which factor is the most important in affecting antioxidant activity. In our study, we obtained four different molecular weight APS by $\mathrm{H}_{2} \mathrm{O}_{2}$ degradation method and the differences of their carboxyl content were small (ranging from $16.2 \%$ to $17.2 \%$ ). Therefore, the influence of the carboxyl group content on the antioxidant ability can be avoided. At the same time, the molecular weight of APS used in our study ranged from 2.60 to $1.03 \mathrm{kDa}$, which is much less than what Chen et al. [5] reported. We also found that only APS with moderate molecular weight showed the greatest antioxidant capacity.

\section{Conclusions}

Three degraded APS with molecular weights of 8.38, 4.72, and $2.60 \mathrm{kDa}$ were obtained by degradation of primitive APS (APS0, Mw $11.03 \mathrm{kDa}$ ) with different concentrations of $\mathrm{H}_{2} \mathrm{O}_{2}$. The results of ${ }^{1} \mathrm{H}$ NMR, ${ }^{13} \mathrm{C}$ NMR, FT-IR, and GCMS showed no significant difference in the main chain structure of the four polysaccharides. All four polysaccharides had $(1 \rightarrow 4)$-D-glucose as the main chain and $(1 \rightarrow 6)-D$-glucose linkage as the branch chain. The monosaccharide component of APS before and after degradation was slightly changed. APS with four molecular weights had the ability to scavenge hydroxyl and ABTS radicals and good reducing ability. The antioxidant capacity of APS was in the following order: APS2 $>$ APS1 $>$ APS0 $>$ APS3, that is, the antioxidant effect of APS2 with moderate molecular weight was the best. Moreover, the polysaccharides showed good ability to enhance SOD activity, inhibit MDA release, and recover cell morphology. APS, especially APS2, can be used as potential antioxidative drugs for renal protection. 


\section{Data Availability}

The data used to support the findings of this study are included within the article.

\section{Conflicts of Interest}

The authors declare no competing financial interest.

\section{Acknowledgments}

This research work was granted by the National Natural Science Foundation of China (nos. 21701050 and 81670644) and the China Postdoctoral Science Foundation (no. 2017M612837).

\section{References}

[1] R. Z. Zhong, M. Yu, H. W. Liu, H. X. Sun, Y. Cao, and D. W. Zhou, "Effects of dietary Astragalus polysaccharide and Astragalus membranaceus root supplementation on growth performance, rumen fermentation, immune responses, and antioxidant status of lambs," Animal Feed Science and Technology, vol. 174, no. 1-2, pp. 60-67, 2012.

[2] Y. Fan, Y. Hu, D. Wang et al., "Effects of Astragalus polysaccharide liposome on lymphocyte proliferation in vitro and adjuvanticity in vivo," Carbohydrate Polymers, vol. 88, no. 1, pp. 68-74, 2012.

[3] Y. Yu, M. Shen, Q. Song, and J. Xie, "Biological activities and pharmaceutical applications of polysaccharide from natural resources: a review," Carbohydrate Polymers, vol. 183, pp. 91-101, 2018.

[4] J. H. Xie, M. L. Jin, G. A. Morris et al., "Advances on bioactive polysaccharides from medicinal plants," Critical Reviews in Food Science and Nutrition, vol. 56, Supplement 1, pp. S60S84, 2015.

[5] R.-Z. Chen, L. Tan, C.-G. Jin et al., "Extraction, isolation, characterization and antioxidant activity of polysaccharides from Astragalus membranaceus," Industrial Crops and Products, vol. 77, pp. 434-443, 2015.

[6] K.-p. Wang, J. Wang, Q. Li et al., "Structural differences and conformational characterization of five bioactive polysaccharides from Lentinus edodes," Food Research International, vol. 62, pp. 223-232, 2014.

[7] M. Jin, K. Zhao, Q. Huang, C. Xu, and P. Shang, "Isolation, structure and bioactivities of the polysaccharides from Angelica sinensis (Oliv.) Diels: a review," Carbohydrate Polymers, vol. 89, no. 3, pp. 713-722, 2012.

[8] J. Fu, L. Huang, H. Zhang, S. Yang, and S. Chen, "Structural features of a polysaccharide from Astragalus membranaceus (Fisch.) Bge. var. mongholicus (Bge.) Hsiao," Journal of Asian Natural Products Research, vol. 15, no. 6, pp. 687-692, 2013.

[9] W. Liu, H. Wang, X. Pang, W. Yao, and X. Gao, "Characterization and antioxidant activity of two low-molecular-weight polysaccharides purified from the fruiting bodies of Ganoderma lucidum," International Journal of Biological Macromolecules, vol. 46, no. 4, pp. 451-457, 2010.

[10] C.-w. Ma, M. Feng, X. Zhai et al., "Optimization for the extraction of polysaccharides from Ganoderma lucidum and their antioxidant and antiproliferative activities," Journal of the Taiwan Institute of Chemical Engineers, vol. 44, no. 6, pp. 886-894, 2013.
[11] J. Sheng and Y. Sun, "Antioxidant properties of different molecular weight polysaccharides from Athyrium multidentatum (Doll.) Ching," Carbohydrate Polymers, vol. 108, pp. 4145, 2014.

[12] P. Wang, X. Jiang, Y. Jiang et al., "In vitro antioxidative activities of three marine oligosaccharides," Natural Product Research, vol. 21, no. 7, pp. 646-654, 2007.

[13] K. W. Kim and R. L. Thomas, "Antioxidative activity of chitosans with varying molecular weights," Food Chemistry, vol. 101, no. 1, pp. 308-313, 2007.

[14] S. R. Khan, "Hyperoxaluria-induced oxidative stress and antioxidants for renal protection," Urological Research, vol. 33, no. 5, pp. 349-357, 2005.

[15] R. Wang, P. Chen, F. Jia, J. Tang, F. Ma, and B. Xu, "Characterization and antioxidant activities of polysaccharides from Panax japonicus C.A. Meyer," Carbohydrate Polymers, vol. 88, no. 4, pp. 1402-1406, 2012.

[16] P. Bhadja, C.-Y. Tan, J.-M. Ouyang, and K. Yu, "Repair effect of seaweed polysaccharides with different contents of sulfate group and molecular weights on damaged HK-2 cells," Polymer, vol. 8, no. 5, p. 188, 2016.

[17] J.-Y. Yin, S.-P. Nie, Q.-B. Guo, Q. Wang, S. W. Cui, and M.Y. Xie, "Effect of calcium on solution and conformational characteristics of polysaccharide from seeds of Plantago asiatica L," Carbohydrate Polymers, vol. 124, pp. 331-336, 2015.

[18] L. Luo, M. Wu, L. Xu et al., "Comparison of physicochemical characteristics and anticoagulant activities of polysaccharides from three sea cucumbers," Marine Drugs, vol. 11, no. 12, pp. 399-417, 2013.

[19] R. Li, W.-c. Chen, W.-p. Wang, W.-y. Tian, and X.-g. Zhang, "Antioxidant activity of Astragalus polysaccharides and antitumour activity of the polysaccharides and siRNA," Carbohydrate Polymers, vol. 82, no. 2, pp. 240-244, 2010.

[20] S. Bhatia, P. Rathee, K. Sharma, B. B. Chaugule, N. Kar, and T. Bera, "Immuno-modulation effect of sulphated polysaccharide (porphyran) from Porphyra vietnamensis," International Journal of Biological Macromolecules, vol. 57, pp. 50-56, 2013.

[21] J. Jiang, F. Kong, N. Li, D. Zhang, C. Yan, and H. Lv, "Purification, structural characterization and in vitro antioxidant activity of a novel polysaccharide from Boshuzhi," Carbohydrate Polymers, vol. 147, pp. 365-371, 2016.

[22] Y. Cai, Q. Luo, M. Sun, and H. Corke, "Antioxidant activity and phenolic compounds of 112 traditional Chinese medicinal plants associated with anticancer," Life Sciences, vol. 74, no. 17, pp. 2157-2184, 2004.

[23] R.-B. Xu, X. Yang, J. Wang et al., "Chemical composition and antioxidant activities of three polysaccharide fractions from pine cones," International Journal of Molecular Sciences, vol. 13, no. 12, pp. 14262-14277, 2012.

[24] K. I. Berker, B. Demirata, and R. Apak, "Determination of total antioxidant capacity of lipophilic and hydrophilic antioxidants in the same solution by using ferric-ferricyanide assay," Food Analytical Methods, vol. 5, no. 5, pp. 1150-1158, 2012.

[25] M. Hassasroudsari, P. Chang, R. Pegg, and R. Tyler, "Antioxidant capacity of bioactives extracted from canola meal by subcritical water, ethanolic and hot water extraction," Food Chemistry, vol. 114, no. 2, pp. 717-726, 2009.

[26] Z. Zhao, J. Li, X. Wu et al., "Structures and immunological activities of two pectic polysaccharides from the fruits of Ziziphus jujuba Mill. cv. jinsixiaozao Hort," Food Research International, vol. 39, no. 8, pp. 917-923, 2006. 
[27] S. C. Chang, B. Y. Hsu, and B. H. Chen, "Structural characterization of polysaccharides from Zizyphus jujuba and evaluation of antioxidant activity," International Journal of Biological Macromolecules, vol. 47, no. 4, pp. 445-453, 2010.

[28] J. Tang, J. Nie, D. Li et al., "Characterization and antioxidant activities of degraded polysaccharides from Poria cocos sclerotium," Carbohydrate Polymers, vol. 105, pp. 121-126, 2014.

[29] S.-g. Li and Y.-q. Zhang, "Characterization and renal protective effect of a polysaccharide from Astragalus membranaceus," Carbohydrate Polymers, vol. 78, no. 2, pp. 343-348, 2009.

[30] J.-Y. Yin, B. C.-L. Chan, H. Yu et al., "Separation, structure characterization, conformation and immunomodulating effect of a hyperbranched heteroglycan from Radix Astragali," Carbohydrate Polymers, vol. 87, no. 1, pp. 667-675, 2012.

[31] L. Sun, L. Wang, J. Li, and H. Liu, "Characterization and antioxidant activities of degraded polysaccharides from two marine Chrysophyta," Food Chemistry, vol. 160, pp. 1-7, 2014.

[32] M. A. Chaouch, J. Hafsa, C. Rihouey, D. Le Cerf, and H. Majdoub, "Depolymerization of polysaccharides from Opuntia ficus indica: antioxidant and antiglycated activities," International Journal of Biological Macromolecules, vol. 79, pp. 779-786, 2015.

[33] C. Q. Qin, Y. M. Du, and L. Xiao, "Effect of hydrogen peroxide treatment on the molecular weight and structure of chitosan," Polymer Degradation and Stability, vol. 76, no. 2, pp. 211-218, 2002.

[34] Y. Li, Y.-L. Wang, L. Li et al., "Structural characterization of polysaccharides from the roots of Urtica fissa," Journal of Asian Natural Products Research, vol. 11, no. 11, pp. 951-957, 2009.

[35] Z.-Y. Zhu, R.-Q. Liu, C.-L. Si et al., "Structural analysis and antitumor activity comparison of polysaccharides from Astragalus," Carbohydrate Polymers, vol. 85, no. 4, pp. 895-902, 2011.

[36] W. Fan, S. Zhang, P. Hao, P. Zheng, J. Liu, and X. Zhao, "Structure characterization of three polysaccharides and a comparative study of their immunomodulatory activities on chicken macrophage," Carbohydrate Polymers, vol. 153, pp. 631-640, 2016.

[37] F. Hecht, C. F. Pessoa, L. B. Gentile, D. Rosenthal, D. P. Carvalho, and R. S. Fortunato, "The role of oxidative stress on breast cancer development and therapy," Tumor Biology, vol. 37, no. 4, pp. 4281-4291, 2016.

[38] C. M. Muth, Y. Glenz, M. Klaus, P. Radermacher, G. Speit, and $\mathrm{X}$. Leverve, "Influence of an orally effective SOD on hyperbaric oxygen-related cell damage," Free Radical Research, vol. 38, no. 9, pp. 927-932, 2009.

[39] H. Chen, H. Yoshioka, G.-S. Kim et al., "Oxidative stress in ischemic brain damage: mechanisms of cell death and potential molecular targets for neuroprotection," Antioxidants \& Redox Signaling, vol. 14, no. 8, pp. 1505-1517, 2011.

[40] F. Tian, Y. Liu, K. Hu, and B. Zhao, "The depolymerization mechanism of chitosan by hydrogen peroxide," Journal of Materials Science, vol. 38, no. 23, pp. 4709-4712, 2003.

[41] S. Alban and G. Franz, "Characterization of the anticoagulant actions of a semisynthetic curdlan sulfate," Thrombosis Research, vol. 99, no. 4, pp. 377-388, 2000.

[42] B. Li, S. Liu, R. Xing et al., "Degradation of sulfated polysaccharides from Enteromorpha prolifera and their antioxidant activities," Carbohydrate Polymers, vol. 92, no. 2, pp. 19911996, 2013.
[43] X. T. Li, Y. K. Zhang, H. X. Kuang et al., "Mitochondrial protection and anti-aging activity of Astragalus polysaccharides and their potential mechanism," International Journal of Molecular Sciences, vol. 13, no. 2, pp. 1747-1761, 2012.

[44] J. Wang, Q. Zhang, Z. Zhang, and Z. Li, "Antioxidant activity of sulfated polysaccharide fractions extracted from Laminaria japonica," International Journal of Biological Macromolecules, vol. 42, no. 2, pp. 127-132, 2008.

[45] J. Fan, Z. Wu, T. Zhao et al., "Characterization, antioxidant and hepatoprotective activities of polysaccharides from Ilex latifolia Thunb," Carbohydrate Polymers, vol. 101, pp. 990997, 2014

[46] J. Wang, S. Hu, S. Nie, Q. Yu, and M. Xie, "Reviews on mechanisms ofin vitroantioxidant activity of polysaccharides," Oxidative Medicine and Cellular Longevity, vol. 2016, Article ID 5692852, 13 pages, 2016.

[47] Y. Chen, H. Zhang, Y. Wang, S. Nie, C. Li, and M. Xie, "Sulfated modification of the polysaccharides from Ganoderma atrum and their antioxidant and immunomodulating activities," Food Chemistry, vol. 186, pp. 231-238, 2015.

[48] F. Lai, Q. Wen, L. Li, H. Wu, and X. Li, “Antioxidant activities of water-soluble polysaccharide extracted from mung bean (Vigna radiata L.) hull with ultrasonic assisted treatment," Carbohydrate Polymers, vol. 81, no. 2, pp. 323-329, 2010.

[49] A. Inoue, N. Kodama, and H. Nanba, "Effect of maitake (Grifola frondosa) D-fraction on the control of the T lymph node Th-1/Th-2 proportion," Biological \& Pharmaceutical Bulletin, vol. 25, no. 4, pp. 536-540, 2002.

[50] H. Qi, T. Zhao, Q. Zhang, Z. Li, Z. Zhao, and R. Xing, "Antioxidant activity of different molecular weight sulfated polysaccharides from Ulva pertusa Kjellm (Chlorophyta)," Journal of Applied Phycology, vol. 17, no. 6, pp. 527-534, 2005.

[51] M. Zhang, X. Tang, F. Wang, Q. Zhang, and Z. Zhang, "Characterization of Lycium barbarum polysaccharide and its effect on human hepatoma cells," International Journal of Biological Macromolecules, vol. 61, pp. 270-275, 2013.

[52] J.-F. Yuan, Z.-Q. Zhang, Z.-C. Fan, and J.-X. Yang, "Antioxidant effects and cytotoxicity of three purified polysaccharides from Ligusticum chuanxiong Hort," Carbohydrate Polymers, vol. 74, no. 4, pp. 822-827, 2008.

[53] I. A. Schepetkin, G. Xie, L. N. Kirpotina, R. A. Klein, M. A. Jutila, and M. T. Quinn, "Macrophage immunomodulatory activity of polysaccharides isolated from Opuntia polyacantha," International Immunopharmacology, vol. 8, no. 10, pp. 1455-1466, 2008.

[54] S. A. Im, S. T. Oh, S. Song et al., "Identification of optimal molecular size of modified Aloe polysaccharides with maximum immunomodulatory activity," International Immunopharmacology, vol. 5, no. 2, pp. 271-279, 2005.

[55] Y. Fan, X. He, S. Zhou, A. Luo, T. He, and Z. Chun, "Composition analysis and antioxidant activity of polysaccharide from Dendrobium denneanum," International Journal of Biological Macromolecules, vol. 45, no. 2, pp. 169-173, 2009. 


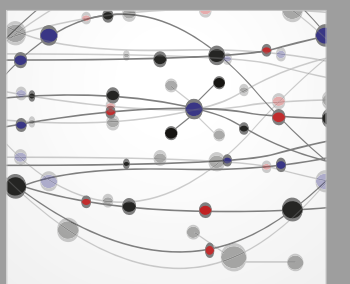

The Scientific World Journal
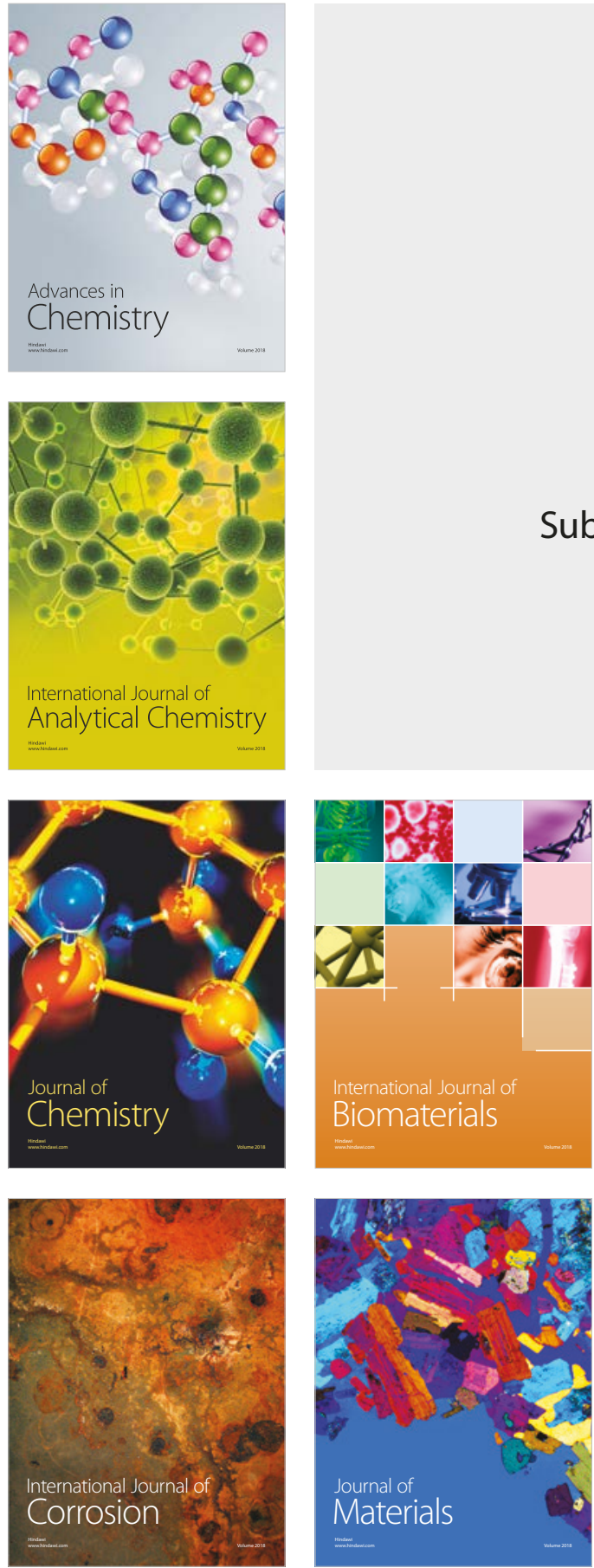

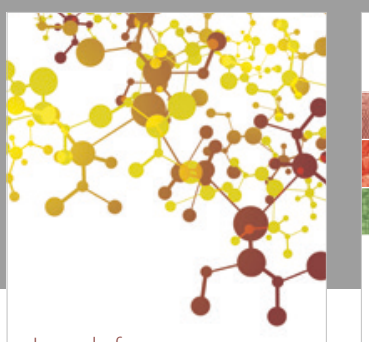

Journal of

Applied Chemistry
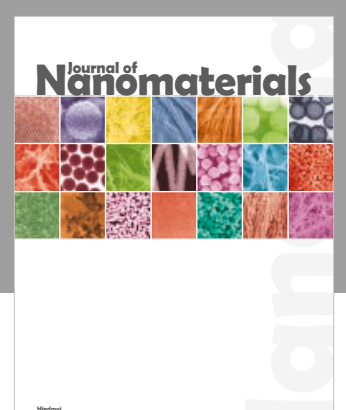

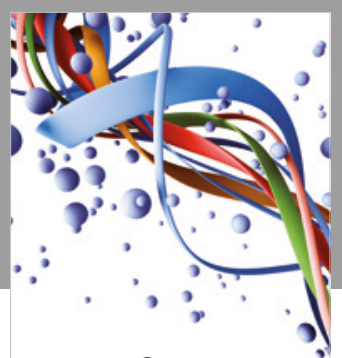

Scientifica

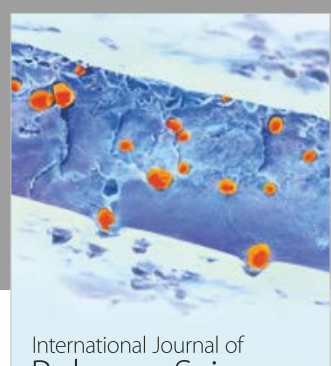

Polymer Science

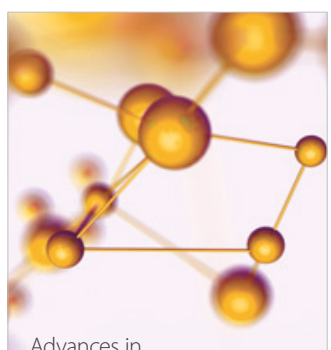

Physical Chemistry
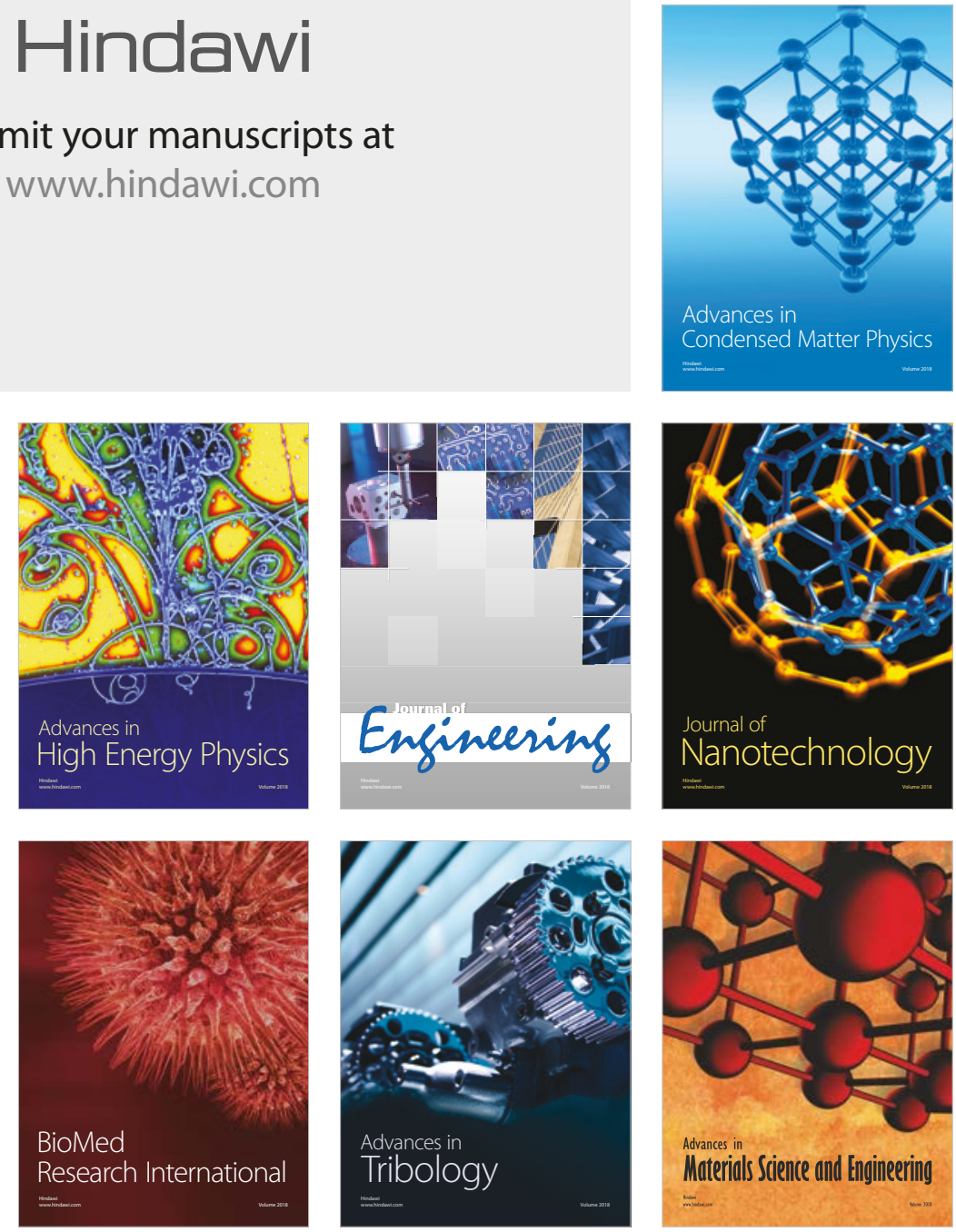